\title{
Tests of the abilities to judge ratios of extensive and intensive sensory magnitudes
}

\author{
Sergio Cesare Masin ${ }^{1} \cdot$ Andrea Brancaccio $^{1} \cdot$ Andrea Tomassetti $^{1}$
}

Published online: 25 March 2019

(C) The Psychonomic Society, Inc. 2019

\begin{abstract}
The assumption that people are able to numerically judge ratios of sensory magnitude is often used to scale sensations. In this study, we tested this assumption for the extensive sensation of length and the intensive sensations of heaviness and brightness. A ratio model fit judged length ratios accurately and fit judged heaviness and brightness ratios inaccurately. Also, most participants could not judge brightness ratios, even if they seemed able to respond nonverbally to the brightness ratios. These results suggest that people may generally be able to judge extensity ratios but not intensity ratios. Participants used auxiliary judgment operations to compensate for their lack of ability to judge intensity ratios. These auxiliary, nonratio operations were found to yield linear scales of intensive sensory magnitude.
\end{abstract}

Keywords Ratio judgment $\cdot$ Extensive sensations $\cdot$ Intensive sensations

Sensations may be roughly classified as extensive, if they change spatially, and as intensive, if they change nonspatially (Fechner, 1887). For example, the length of a line is an extensive sensation, and the heaviness of a lifted object or the brightness of a surface are intensive sensations.

Psychophysicists conjecture that people can judge sensory ratios numerically by uttering numerals with values proportional to the respective sensory ratios (Merkel, 1888; Richardson, 1929; S. S. Stevens, 1975). This hypothesis is often used to measure extensive and intensive sensations (Gescheider, 1997; Laming, 1997; Marks, 1974). ${ }^{1}$ We tested the validity of this hypothesis for judgments of ratios of length, heaviness, and brightness.

The history of the hypothesis that people are able to judge sensory ratios is long and still alive today. When Merkel (1888) first set forth this hypothesis, James (1890) and

\footnotetext{
${ }^{1}$ It is also of practical importance, because such judgments are largely used for evaluating aspects of people's lives including pain, preference, usability, professionalism, stress, food quality, hedonics, sentence acceptability, and many others (Faleiros Sousa \& Hortense, 2006; Lawless \& Heymann, 2010; Lim, 2011; Rahe, Veach, Tolles, \& Murakami, 2000; Ruskin, Amaria, Warnock, \& McGrath, 2011; Sprouse, 2011; Utamura, Murase, Hamatani, \& Nagano, 2009; Zinnes \& MacKay, 1989).
}

Sergio Cesare Masin scm@unipd.it

1 Department of General Psychology, University of Padua, Padua, Italy
Wundt (1907) promptly objected that it was unconvincing. Richardson (1929) revived the hypothesis, inspiring engineers to use it for measuring loudness (Geiger \& Firestone, 1933; Ham \& Parkinson, 1932; Laird, Taylor, \& Wille, 1932). The ratio judgment hypothesis gained widespread acceptance in psychology as soon as S. S. Stevens (1936) endorsed it. It is a focus of various theoretical discussions today (Augustin, 2010; Luce, 2012; Rossi \& Berglund, 2011).

Using ordinal tests, researchers have found unanimously that people judge sensory ratios inaccurately. The following are two examples of such tests. Svenson and Åkesson (1966) asked participants, given the sensory magnitudes $\Psi_{a}$ and $\Psi_{b}$, to make numerical judgments $J_{1}$ and $J_{2}$ of the ratios $\rho_{1}=\Psi_{a} / \Psi_{b}$ and $\rho_{2}=$ $\Psi_{b} / \Psi_{a}$, respectively. Although $\rho_{1} \cdot \rho_{2}=1$, it turned out that $J_{1}$. $J_{2} \neq 1$. For the sensory magnitudes $\Psi_{a}, \Psi_{b}$, and $\Psi_{c}$, Fagot and Stewart (1969) asked participants to make the numerical judgments $J_{1}, J_{2}$, and $J_{3}$ of $\rho_{1}=\Psi_{a} / \Psi_{b}, \rho_{2}=\Psi_{b} / \Psi_{c}$, and $\rho_{3}=\Psi_{a} / \Psi_{c}$, respectively. Although $\rho_{1} \cdot \rho_{2}=\rho_{3}$, it turned out that $J_{1} \cdot J_{2} \neq$ $J_{3}$. These tests suggest that people judge sensory ratios inaccurately. Other similar ordinal tests have led to the same conclusion (Augustin \& Maier, 2008; Ellermeier \& Faulhammer, 2000; Westermann, 1982; Zimmer, 2005).

Ordinal tests of the ratio judgment hypothesis suffer from the following drawbacks. Although these tests unanimously suggest that people numerically judge sensory ratios inaccurately, they fail to discriminate between degrees of judgment inaccuracy, for the very reason that they are ordinal in nature. 
More importantly, ordinal tests are also completely mute regarding possible nonratio judgment operations that people might use to compensate for their inability to judge ratios.

We tackled the issue of whether numerical judgments of sensory ratios represent sensory ratios accurately by using principles of integration psychophysics (Anderson, 1990, 1992, 2008; Gescheider, 1997; McBride, 1993; McBride \& Anderson, 2014; Weiss, 2006). In the event that the tests indicate an inability to judge ratios, these principles also offer the advantage over ordinal tests of providing indications of alternative judgment operations that people might be using to carry out the experimenter-required task to judge ratios. We start with an overview of these principles.

Consider the task of numerically judging the ratio between two sensory magnitudes of the same type, $\Psi_{S}$ and $\Psi_{V}$, with $\Psi_{S}$ $<\Psi_{V}$. In the event that people are able to judge the unit ratio of $\Psi_{V}$ to $\Psi_{S}$, integration psychophysics assumes that they would integrate $\Psi_{S}$ and $\Psi_{V}$ into the implicit response

$\rho=a_{1} \cdot \frac{\Psi_{V}}{\Psi_{S}}$,

with $a_{1}$ being a parameter (Anderson, 1981, 1982).

The theory further assumes that the numerical judgment of the unit ratio of $\Psi_{V}$ to $\Psi_{S}$ is

$J=a_{2}+a_{3} \cdot \rho$,

with $a_{2}$ and $a_{3}$ being parameters. Much evidence supports this assumption when stimuli are judged on a scale with ends defined by anchor stimuli (Anderson, 1996, pp. 94-96). It follows that

$J=a_{2}+a_{4} \cdot \frac{\Psi_{V}}{\Psi_{S}}$

with $a_{2}$ and $a_{4}$ being parameters expressing that the origin and unit of the judgment scale are arbitrary.

Equation 3 implies that, if $\Psi_{S}$ and $\Psi_{V}$ could be measured, plotting $J$ against the measures of $\Psi_{V}$ for each fixed measure of $\Psi_{S}$ would yield straight lines forming a fanlike pattern. One could test the validity of model Eq. 3 by verifying whether this fanlike pattern of straight lines occurs empirically (Anderson, 1974a, 1981, 1982). The following experiments provided this test for the extensive sensation of length and the intensive sensations of heaviness and brightness. We begin with considering judgments of ratios of lengths.

\section{Length}

People can numerically judge ratios between pairs of lengths in the frontoparallel plane by very quickly counting how many times the shorter length is contained in the longer length (Hartley, 1977, 1981; Krantz, 1972; Masin, 2013; Masin \&
Anali, 2011; Reed, Hock, \& Lockhead, 1983). This ability receives support from the finding of a high correlation between judgments of ratios of perceived distance and the corresponding ratios of physical distance (Baird, 1970; Norman et al., 2017; Norman, Adkins, \& Pedersen, 2016).

However, studies have not yet established whether numerical judgments of ratios of perceived length accurately represent the ratios of perceived length being judged. That is, it is unknown whether the summation of mental length units in mental counting occurs correctly, and whether the high correlation between judgments of ratios and the actual ratios occurs because these judgments are accurate or are only approximate representations of the ratios being judged.

\section{Experiment 1}

We used the basic assumption that a perceived frontal length is proportional to the corresponding physical frontal length. This assumption receives support from findings that perceptual geometrical relationships in the frontal plane may match the corresponding physical geometrical relationships and from findings that quantitative relationships between the cognitive and perceptual counterparts of variables of extended physical phenomena may match the corresponding physical relationships (Algom \& Cohen-Raz, 1984, 1987; Algom, Wolf, \& Bergman, 1985; Anderson, 1983; Anderson \& Weiss, 1971; De Sá Teixeira, Oliveira, \& Silva, 2014; Krist, Fieberg, \& Wilkening, 1993; Lanca \& Bryant, 2001; Masin, 2016a; Weiss \& Gardner, 1979; Wilkening, 1981, 1982). ${ }^{2}$

The experiment used pairs of perceived lengths $\lambda_{S}$ and $\lambda_{V}$ combined factorially, with $\lambda_{S}<\lambda_{V}$ in each pair. Participants were asked to judge in each pair how many times $\lambda_{V}$ was larger than $\lambda_{S}$.

Equation 3 asserts that a model for this judgment is

$J=b_{1}+b_{2} \cdot \frac{\lambda_{V}}{\lambda_{S}}$

with $b_{1}$ and $b_{2}$ being parameters. Let $L_{S}$ and $L_{V}$ denote the physical lengths corresponding to $\lambda_{S}$ and $\lambda_{V}$, respectively. The assumption that perceived length is proportional to physical length implies that

$J=b_{1}+b_{2} \cdot \frac{L_{V}}{L_{V}}$.

\footnotetext{
${ }^{2}$ For all practical purposes, in the present study this assumption could be considered valid because stimulus length varied in a rather narrow range. Broadly supporting this assertion, the methods of bisection, functional measurement, magnitude estimation, mental counting, nonmetric scaling, and rating with anchors have all been found to yield measures of perceived length that are linearly related to physical length (Anderson, 1974b; Baird, 1970; Bogartz, 1979; Masin, 2008; Schneider \& Bissett, 1988; S. S. Stevens \& Guirao, 1963: Wagner, 2006; Weiss \& Anderson, 1969).
} 
Equation 5 is formally equivalent to Eq. 4. Testing whether Eq. 5 is an accurate model of ratio judgment is thus equivalent to testing whether Eq. 4 is an accurate model of ratio judgment. In the experiment, we thus tested whether Eq. 5 predicts judged length ratios accurately.

\section{Method}

Participants and stimuli Twenty-nine psychology students with a mean age of 22 years participated in the experiment. The stimuli were 1-mm-thick horizontal black lines presented in a dark room for $1.5 \mathrm{~s}$ on a $111 \times 58 \mathrm{~cm}, 30-\mathrm{cd} / \mathrm{m}^{2}$ gray area on the flat, frontoparallel screen of a computer monitor. The viewing distance was about $130 \mathrm{~cm}$. A 0.3 -s beep was presented $1 \mathrm{~s}$ before the onset of each stimulus.

Ten stimuli were used. Four had a length $L_{S}$ of $2,4,6$, or 8 $\mathrm{cm}$, and six had a length $L_{V}$ of $10,12,14,16,18$, or $20 \mathrm{~cm}$. Each trial consisted of presenting two successive stimuli separated by a time interval of $6 \mathrm{~s}$, one with length $L_{S}$, on the left, and one with length $L_{V}$, on the right of the screen. The stimuli appeared in a random location inside a $23 \times 24 \mathrm{~cm}$ nondrawn area. The left side of this area was located $11 \mathrm{~cm}$ from the screen's left side for stimuli with length $L_{S}$, and was located $36 \mathrm{~cm}$ from the screen's right side for stimuli with length $L_{V}{ }^{3}$

Two blocks of 24 randomly ordered trials were presented consecutively. In each block, each trial had a different combination of $L_{S}$ and $L_{V}$. The left stimulus $\left(L_{S}\right)$ was presented first on each trial of one block, and the right stimulus $\left(L_{V}\right)$ was presented first on each trial of the other block. The mean duration of the administration of all trials was $11.5 \mathrm{~min}$.

Procedure Participants were instructed to judge on each trial how many times the right stimulus was longer than the left stimulus. They were asked to verbally express their judgments as decimal numbers. They were given no example of these numerical judgments.

\section{Results and discussion}

Figure 1 shows the mean judged ratios, plotted against $L_{V}$ for each $L_{S}$. The left diagram shows the results for the right stimulus presented before the left stimulus (" $L_{V}$ before $L_{S}$ "), and the right diagram shows those for the right stimulus presented after the left stimulus (" $L_{V}$ after $L_{S}$ ").

The mean judged ratios were larger in the order condition " $L_{V}$ after $L_{S}$." This overestimation increased with $L_{V}$. The following analysis supports these order effects.

A $2(O$ : order $) \times 4\left(L_{S}\right) \times 6\left(L_{V}\right)$ analysis of variance (ANOVA) indicated that the effect of $O$ and the interactions

\footnotetext{
${ }^{3}$ Stimuli were presented in random positions so as to reduce the probability that participants would focus on the distance of the ends of lines from the screen border instead of focusing on the line length per se.
}

$O \times L_{V}$ and $L_{S} \times L_{V}$ were significant, $F(1,28)=33\left(\eta_{\mathrm{p}}^{2}=.54\right)$, $F(5,140)=3.7\left(\eta_{\mathrm{p}}{ }^{2}=.12\right)$, and $F(15,420)=10.8\left(\eta_{\mathrm{p}}{ }^{2}=.28\right)$, respectively, $p \mathrm{~s}<.005$, and the interaction $O \times L_{S}$ and the three-factor interaction were not significant, $F(3,84)<1$ and $F(15,420)<1$, respectively.

In agreement with the hypothesis that participants judged length ratios, Fig. 1 shows that the factorial curves were statistically equivalent to a fanlike pattern of hyperbolically spaced straight lines. For $L_{V}$, the linear trend was significant and the quadratic trend nonsignificant, $F(1,28)=244\left(\eta_{\mathrm{p}}{ }^{2}=.90\right), p<$ .001 , and $F(1,28)<1$, whereas for $L_{S}$, the linear and quadratic trends were both significant, $F(1,28)=367\left(\eta_{\mathrm{p}}^{2}=.93\right), p<$ .001 , and $F(1,28)=133\left(\eta_{\mathrm{p}}{ }^{2}=.83\right), p<.001$, respectively.

Equation 5 fits the data inaccurately. A least-squares fit of Eq. 5 to the data yielded the parameter estimates $b_{1}=0.65$ and $b_{2}=0.72$ for " $L_{V}$ before $L_{S}$," and $b_{1}=0.88$ and $b_{2}=0.77$ for " $L_{V}$ after $L_{S}$." In Fig. 1, the dashed straight lines represent the mean judged ratios predicted by Eq. 5 using these parameter estimates. It may be seen that the fit of the model is somewhat poor. The following statistical analysis supports this conclusion.

The algebraic differences between the judged length ratios and the respective $J_{\mathrm{s}}$ obtained from Eq. 5 by using the above parameter estimates were calculated. A $2(O) \times 4\left(L_{S}\right) \times 6\left(L_{V}\right)$ ANOVA was performed on these differences. If Eq. 5 fit the data accurately, this accuracy would be shown by a lack of significance of all the factors and interactions. The effects of $L_{S}$ and $L_{V}$ turned out to be significant, $F(3,84)=3.0\left(\eta_{\mathrm{p}}{ }^{2}=\right.$ $.10), p<.05$, and $F(5,140)=7.9\left(\eta_{\mathrm{p}}{ }^{2}=.22\right), p<.005$, respectively. All of the interactions were not significant: $F(3,84)<1$ $\left(O \times L_{S}\right), F(5,140)=2.2\left(O \times L_{V}\right), F(15,420)=1.1\left(L_{S} \times L_{V}\right)$, and $F(15,420)<1\left(O \times L_{S} \times L_{V}\right)$.

The significant effects of $L_{S}$ and $L_{V}$ indicate that participants judged the perceived length ratios inaccurately. Because the lengths were presented successively, the judged length ratios may have been inaccurate because participants actually judged the ratios of remembered or remembered/ perceived lengths rather than only of the perceived lengths.

The poor predictions of Eq. 5 suggest that remembered length might have been nonproportional to the perceived length. The significant linear trend and nonsignificant quadratic trend found for $L_{V}$ suggest a linear nonproportionality between remembered and perceived length. Assuming this linear nonproportionality, after some simplification Eq. 1 becomes

$\rho=b_{3} \cdot \frac{b_{4}+\lambda_{V}}{b_{5}+\lambda_{S}}$,

with $b_{3}-b_{5}$ being parameters. The proportionality of perceived to physical length implies that

$J=b_{1}+b_{3} \cdot \frac{b_{6}+L_{V}}{b_{7}+L_{S}}$,

with $b_{6}$ and $b_{7}$ also being parameters. 

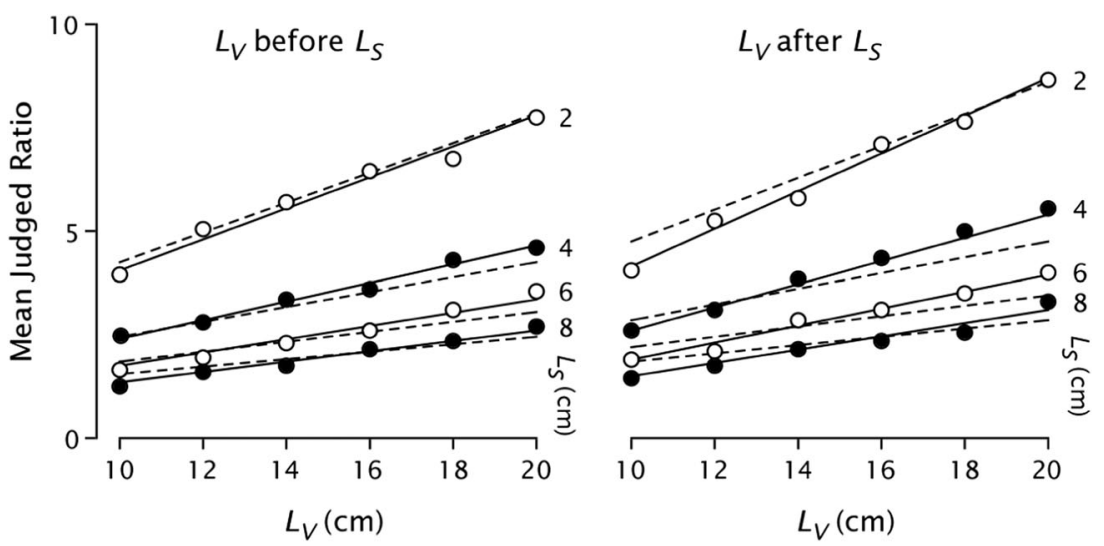

Fig. 1 Mean judged ratios of perceived length for pairs of successive lines having physical length $L_{S}$ or $L_{V}$, with $L_{V}$ having been presented either before or after $L_{S}$. The dashed fitting lines represent the predictions from the model in Eq. 5, and the solid fitting lines show predictions from the model in Eq. 7

Equation 7 fit the data accurately. One may set $b_{1}=0$ in Eq. 7 when considering that $J$, rather than being a response on a continuous judgment scale, was most probably a discrete mental count of how many times the shorter of the two compared lengths was contained in the longer length (Hartley, 1977; Krantz, 1972; Masin \& Anali, 2011). For $b_{1}=0$, a least-squares fit of Eq. 7 to the data yielded the parameter estimates $b_{3}=1.12, b_{6}=0.35$, and $b_{7}=0.49$ for " $L_{V}$ before $L_{S}$," and $b_{3}=1.5, b_{6}=-0.47$, and $b_{7}=0.64$ for " $L_{V}$ after $L_{S}$." In

Fig. 1, the solid straight lines represent the mean judged ratios predicted by Eq. 7 using these parameter estimates for $b_{1}=0$. It may be seen that these lines fit the data well. The following statistical analysis supports this conclusion.

A $2(O) \times 4\left(L_{S}\right) \times 6\left(L_{V}\right)$ ANOVA was carried out on the algebraic differences between the judged length ratios and the respective $J \mathrm{~s}$ obtained from Eq. 7 using the least-squares parameter estimates for $b_{1}=0$. The effects of the factors and the interactions all turned out not to be significant, all $F$ ratios $<1$. This finding of a good fit of Eq. 7 to the data suggests that participants may have judged length ratios using remembered lengths to some extent.

\section{Cautionary remark}

It may be worthwhile to stress that the present findings have only indicative value. The better fit of Eq. 7 to the data does not verify the cognitive processes assumed by this equation, given that other possible models based on different assumptions might yield equally good fits to the data. Also, the worse fit of Eq. 5 to the data does not mean that this equation is an invalid model. Such model indeterminacy is a general problem, because model selection simultaneously depends on the properties of the unknown source model - the actual cognitive process - and of the fitted model. These properties are the socalled fertility of the source model and the complexity and functional form of the fitted model (Collyer, 1988; Myung, 2000). Numerical simulations have shown, perhaps counterintuitively, that a fitted model may fit data inaccurately even when the fitted model is the source model (Collyer, 1985).

\section{Conclusion}

Because the stimuli were pairs of successive lines presented briefly, the length ratio in each pair comprised at least one remembered length rather than only perceived lengths. Equation 7 was based on the empirically supported basic assumption that perceived length is related linearly to physical length. As long as this assumption holds, the good fit of Eq. 7 to the data offers evidence for the first time that people may be able to accurately judge ratios of two remembered extensive magnitudes or between a remembered and a perceived extensive magnitude. Because remembered length differed only slightly from the corresponding perceived length, the judged ratios between remembered lengths or between remembered and perceived lengths may be considered roughly equivalent to the corresponding ratios between perceived lengths.

\section{Heaviness}

Holmin and Norman (2012) obtained data suggesting that people can judge sensory intensity ratios. They had participants lift pairs of objects and then carry out the task of judging the ratio of the heavier object weight relative to the lighter one. It turned out that participants judged the ratios with rather remarkable accuracy: For young adults, the best-fitting regression line relating the judged ratios to the physical weight ratios had an average slope of 1.32 .

The judgment accuracy found by Holmin and Norman (2012) might suggest that people are able to judge heaviness ratios. However, the following results indicated that such accuracy might derive from a judgment operation close to but 
different from the ratio operation. For heaviness values $\omega_{S}$ and $\omega_{V}$ combined factorially, $\omega_{S}<\omega_{V}$, participants were asked to judge the unit ratio $\omega_{V} / \omega_{S}$ in each pair while they were bimanually lifting the respective stimulus weights. They judged the heaviness ratios for weights from 5 to $10 \mathrm{hg}$. Within this range, magnitude estimation studies have suggested that heaviness is proportional to weight (Marks \& Cain, 1972; J. C. Stevens \& Rubin, 1970). Accordingly, within this range, judgments of the ratio $\omega_{V} / \omega_{S}$ should be

$J=c_{1}+c_{2} \cdot \frac{W_{V}}{W_{S}}$,

with $W_{S}$ and $W_{V}$ being the weights proportional to $\omega_{S}$ and $\omega_{V}$, respectively, and $c_{1}$ and $c_{2}$ being parameters. ${ }^{4}$

For equispaced values of $W_{S}$ and $W_{V}$, Eq. 8 implies that the factorial curves relating $J$ to $W_{V}$ would form a fan of hyperbolically spaced straight lines - that is, that the factorial curves relating $J$ to $W_{V}$ would form a fan of straight lines, and those relating $J$ to $W_{S}$ would form a fan of hyperbolas. Instead, the empirical factorial curves relating $J$ to $W_{V}$ have been found to form a set of equispaced diverging straight lines - that is, both the curves relating $J$ to $W_{V}$ and those relating $J$ to $W_{S}$ formed a fan of straight lines (Masin \& Brancaccio, 2017). One might thus hypothesize that participants judged some quantitative relationship between pairs of heaviness values that was not a heaviness ratio. Experiments 2 and 3 served to explore this hypothesis.

\section{Experiments 2 and 3}

Dimensional differences between factorial designs might differentially affect the spacing of factorial curves (Greenwald, 1976; Grice, 1966; Mullet \& Chasseigne, 2018; Weiss, 2014). To obviate this potential confounding effect, we had participants judge heaviness ratios and length ratios under the same design conditions. Because people seem to judge length ratios accurately, one would expect that under the same design conditions the patterns of factorial curves for heaviness and length would be the same only if participants were also able to judge heaviness ratios.

Prior experiments had investigated judgments of heaviness and length ratios using simultaneous and successive stimuli, respectively. To increase our study's generality, we used simultaneous and successive stimuli for each type of ratio. Experiment 2 used heaviness data, and Experiment 3, length data.

\footnotetext{
${ }^{4}$ Within a narrow stimulus range, a psychophysical power function may be considered linear for all practical purposes even when it is largely nonlinear outside the stimulus range. Thus, in the present study, heaviness could a fortiori be considered proportional to weight because the weight range used was narrow.
}

The results of Experiment 1 suggested that memory influenced judged sensory ratios. That memory could affect judged ratios is suggested by the fact that the exponent of the psychophysical power function obtained by magnitude estimation may be lower for remembered sensations than for the corresponding perceived sensations (Hubbard, 1994). It is currently unclear whether the psychophysical power exponent for remembered sensations declines with the passage of time, because some studies have shown that it does, and some have shown that it does not (Hubbard \& Baird, 1988; Kemp, 1988; Kerst, Howard, \& Gugerty, 1987). Experiments 2 and 3 additionally served to explore whether memory might affect judged sensory ratios by testing whether the judged ratios varied with the time interval between successively compared stimuli.

\section{Experiment 2}

\section{Method}

Participants and stimuli Twenty-two psychology students with a mean age of 22.6 years participated in the experiment. None had taken part in Experiment 1.

The stimuli were ten cylindrical cans of $8.5-\mathrm{cm}$ diameter and 10-cm height. Four had a weight $W_{S}$ of 1, 2, 3, or $4 \mathrm{hg}$ and were lifted with the left hand. The other six had a weight $W_{V}$ of $5,6,7,8,9$, or $10 \mathrm{hg}$ and were lifted with the right hand.

A vertical $135 \times 62 \mathrm{~cm}$ screen with its base edge coinciding with the edge of a table had two $17 \times 9 \mathrm{~cm}$ holes spaced $18 \mathrm{~cm}$ apart symmetrically about the screen's central axis. The bases of the holes coincided with the table edge. Participants reached the stimuli through these holes. On each trial, the stimuli were placed on the table about $10 \mathrm{~cm}$ from the corresponding hole. The participants were allowed to see the stimuli only after the end of the experiment.

Participants were asked to lift each stimulus only once, for about $0.5 \mathrm{~s}$. They practiced this lifting four times. Before each trial, participants were told whether they were to lift the stimuli simultaneously or successively. A 0.3 -s beep signaled when to start lifting.

For simultaneous-lifting trials, after the beep signal the participants grasped and lifted the stimuli simultaneously by inserting their left and right hands through the corresponding holes.

For successive-lifting trials, the beep signal was presented twice. The first beep signaled when to lift the left stimulus using the left hand, and the second when to lift the right stimulus using the right hand. At the first signal, participants inserted their left hand in the left hole, lifted the left stimulus, retracted their left hand, and then waited. At the second signal, they inserted their right hand in the right hole, lifted the right stimulus, and then reported their judgment. 
On each trial, the weight of the left stimulus was $W_{S}$ and that of the right stimulus was $W_{V}$. There were four blocks of 24 trials, with a different combination of $W_{S}$ and $W_{V}$ for each trial of a block. On each trial of each of three blocks, the left stimulus was lifted before the right stimulus, and the time interval between the respective beep signals was 4,12 , or 36 s. On each trial of the remaining block, the stimuli were lifted simultaneously. Trials were presented consecutively in a randomly intermixed order. The mean duration of the administration of all trials was $37 \mathrm{~min}$.

Procedure Participants were instructed to judge on each trial how many times the right stimulus was heavier than the left stimulus. They were asked to verbally express their judgments as decimal numbers. They were given no example of these numerical judgments.

\section{Experiment 3}

\section{Method}

Participants and stimuli Twenty-two psychology students with a mean age of 21.7 years participated in the experiment for course credit. None had taken part in Experiment 1 or 2.

The stimuli and presentation conditions were the same as those used in Experiment 1. On each trial, one stimulus with length $L_{S}$ was presented on the left side of the screen, and one with length $L_{V}$ on the right side. There were four blocks of 24 trials, with a different combination of $L_{S}$ and $L_{V}$ for each trial of a block. On each trial of each of three blocks, the left stimulus was presented before the right stimulus with an interstimulus interval of 4, 12, or $36 \mathrm{~s}$. On each trial of the remaining block, the stimuli were presented simultaneously. Trials were presented consecutively in randomly intermixed order. The mean duration of the administration of all trials was $34 \mathrm{~min}$.

Procedure The procedure was the same as that in Experiment 1.

\section{Results and discussion}

Figure 2 shows the mean judged ratios of heaviness and length plotted against $W_{V}$ and $L_{V}$ for each $W_{S}$ and $L_{S}$, respectively, and for each time interval - that is, depending on the trial, each time interval between the two beeps that signaled when to start lifting the weight stimuli, or each interstimulus interval between the line stimuli. The " $0 \mathrm{~s}$ " time interval means simultaneous presentation of the stimuli. The following results suggest the use of different judgment operations for heaviness and length.

For each time interval, the factorial curves for heaviness and length look roughly equispaced and hyperbolically spaced, respectively. The following analyses support this difference in results. For heaviness, the linear trends for $W_{S}$ and
$W_{V}$ were significant, $F(1,21)=22.4\left(\eta_{\mathrm{p}}{ }^{2}=.52\right)$ and $F(1,21)=$ $19.7\left(\eta_{\mathrm{p}}{ }^{2}=.48\right), p \mathrm{~s}<.001$, and the quadratic trends were not significant, $F(1,21)<1$ and $F(1,21)=1.67$, respectively. For length, the linear and quadratic trends were significant for $L_{S}, F(1,21)=402\left(\eta_{\mathrm{p}}{ }^{2}=.95\right)$ and $F(1,21)=120\left(\eta_{\mathrm{p}}{ }^{2}=.85\right)$, $p s<.001$, whereas the linear trend was significant and the quadratic trend was not significant for $L_{V}, F(1,21)=425$ $\left(\eta_{\mathrm{p}}{ }^{2}=.96\right), p<.001, F(1,21)=3.51$, respectively.

For heaviness, separate $4\left(W_{S}\right) \times 6\left(W_{V}\right)$ ANOVAs showed significant interactions for the time intervals of 0 and $4 \mathrm{~s}, F(15$, $315)=2.6\left(\eta_{\mathrm{p}}{ }^{2}=.11\right)$ and $F(15,315)=2.4\left(\eta_{\mathrm{p}}{ }^{2}=.10\right), p \mathrm{~s}<$ .005 , and nonsignificant interactions for the time intervals of 12 and $36 \mathrm{~s}, F(15,315)<1$ for both. Thus, the factorial curves diverged significantly for time intervals up to $4 \mathrm{~s}$ and were statistically parallel for time intervals longer than $4 \mathrm{~s}$.

Experimental evidence suggests that, after a lifted object is set down, the corresponding sensory haptic information persists for a few seconds before it is converted into short-term haptic memory information (Kiphart, Hughes, Simmons, \& Cross, 1992; Shih, Dubrowski, \& Carnahan, 2009). The results for heaviness agree with the possibility that judgments were prevalently based on ongoing or persisting haptic information for time intervals up to about $4 \mathrm{~s}$, and on short-term haptic memory information for time intervals longer than about $4 \mathrm{~s}$.

For length, separate $4\left(L_{S}\right) \times 6\left(L_{V}\right)$ ANOVAs showed that the factorial curves significantly diverged for each time interval from 0 to $36 \mathrm{~s}$. The interaction was significant for each of these time intervals: $F(15,315)=8.3\left(\eta_{\mathrm{p}}{ }^{2}=.28\right), F(15,315)=$ $6.2\left(\eta_{\mathrm{p}}{ }^{2}=.23\right), F(15,315)=5.8\left(\eta_{\mathrm{p}}{ }^{2}=.22\right)$, and $F(15,315)=$ $5.7\left(\eta_{\mathrm{p}}^{2}=.21\right)$, respectively, $p \mathrm{~s}<.001$.

Figure 3 shows mean judged heaviness ratios calculated across $W_{S}$ values, and mean judged length ratios calculated across $L_{S}$ values, plotted, respectively, against $W_{V}$ and $L_{V}$ separately for each time interval. Judged heaviness ratios were smaller for simultaneous stimuli, supporting the previous consideration that judgments might have differently depended on ongoing haptic information, when the stimuli were simultaneous, and on haptic memory information, when the stimuli were successive. In Fig. 3, the results for heaviness at $0 \mathrm{~s}$ are exceptional, both in relation to the heaviness results at other time intervals and to the length results at all time intervals. The lifting of two objects at the same time, one with each hand, seems to ensure simultaneous input from both objects. Yet the simultaneous presentation of two lines does not guarantee simultaneous comparison of the lines. It may be that lines were compared by using successive eye fixations and/or successive allocation of attention: The same pattern of errors in comparative judgments of line lengths has indeed been observed for both successive lines and simultaneous lines presented briefly enough to prevent eye movements (Masin \& Agostini, 1990, 1991). It thus might be that the exceptional results for heaviness at $0 \mathrm{~s}$ can be attributed to a stricter simultaneity of inputs. 
Fig. 2 Mean judged ratios of perceived heaviness for pairs of physical weights $W_{S}$ and $W_{V}$, and mean judged ratios of perceived length for pairs of lines of physical length $L_{S}$ and $L_{V}$ for the indicated time intervals between pairs of weights and between pairs of lines, respectively

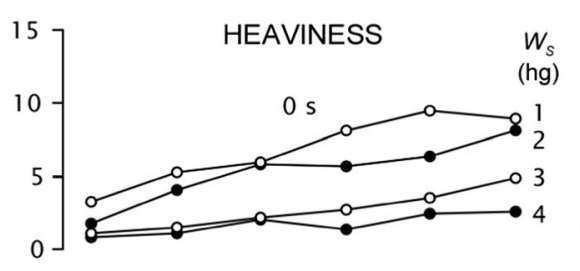

$W_{s}$

LENGTH
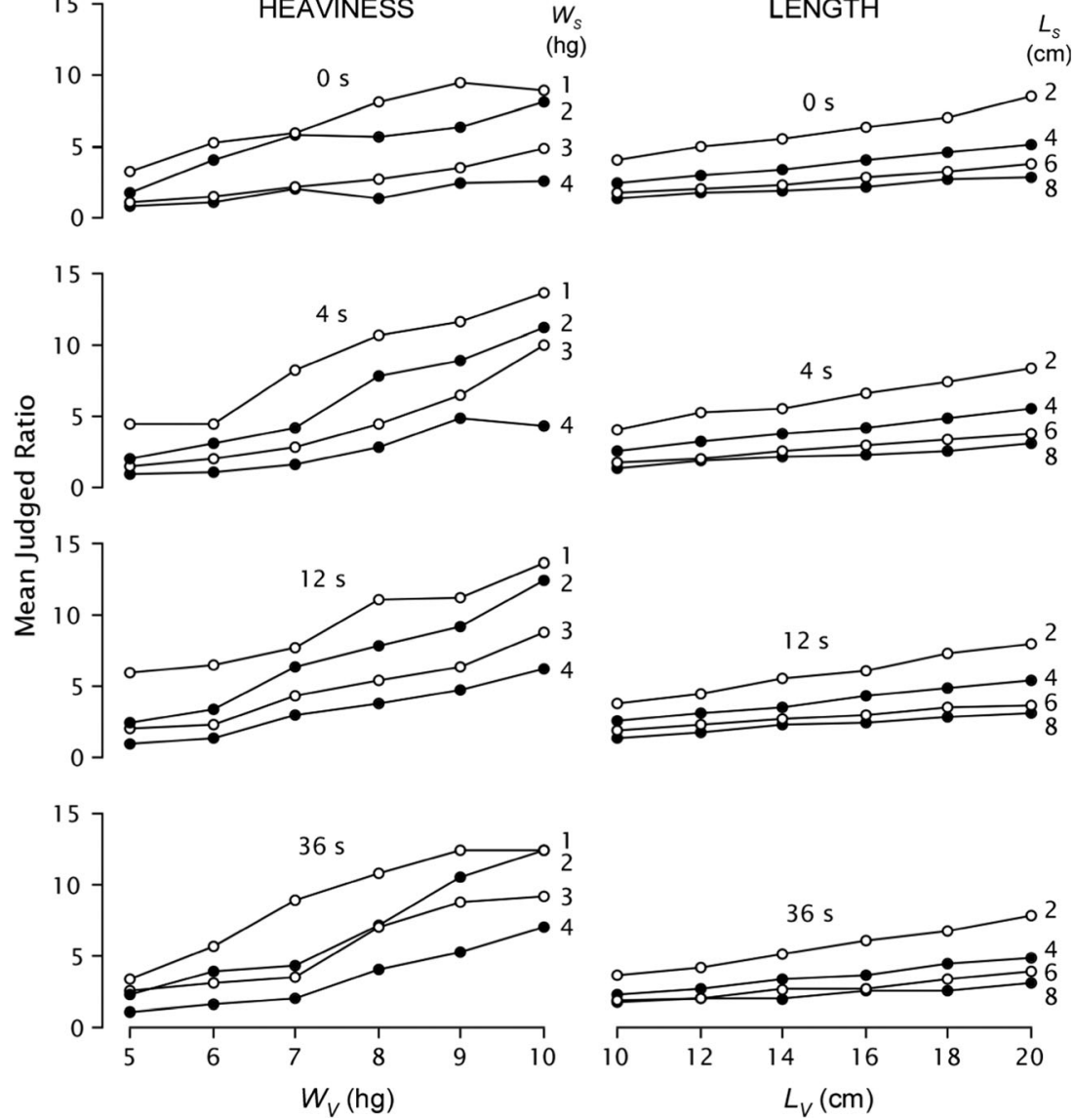

A 4 (time interval) $\times 6$ (either $W_{V}$ or $L_{V}$ ) ANOVA showed that the effect of time interval and the interaction were significant for heaviness, $F(3,63)=9.4\left(\eta_{\mathrm{p}}{ }^{2}=.31\right)$ and $F(15,315)=$ $2.3\left(\eta_{\mathrm{p}}{ }^{2}=.10\right)$, respectively, $p \mathrm{~s}<.005$, whereas the effect of time interval was significant and the interaction was not significant for length, $F(3,63)=3.3\left(\eta_{\mathrm{p}}{ }^{2}=.14\right), p<.05$, and $F(15,315)<1$, respectively.

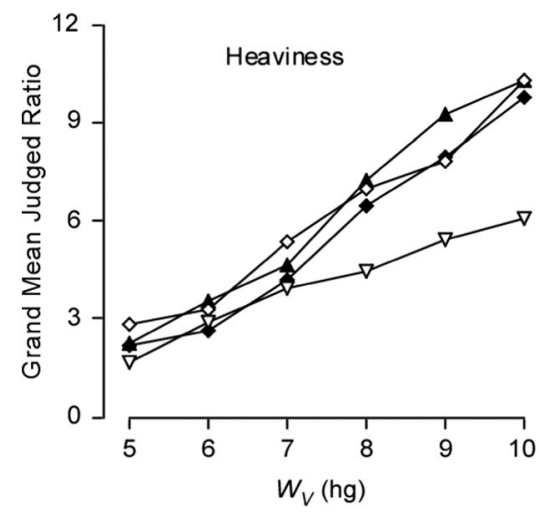

Fig. 3 For pairs of physical weights $W_{S}$ and $W_{V}$ and pairs of physical line lengths $L_{S}$ and $L_{V}$ separated by time intervals of $0-36 \mathrm{~s}$, the mean judged ratios of perceived heaviness and perceived length are shown, as
Figure 4 shows, for each time interval, the grand variances of judged heaviness ratios and of judged length ratios, calculated over all participants and all combinations of $W_{S}$ and $W_{V}$ and of $L_{S}$ and $L_{V}$, respectively. Judgment variability was higher for successive than for simultaneous weight stimuli, was higher for weight than for line stimuli, and was essentially the same for successive and simultaneous line stimuli. For

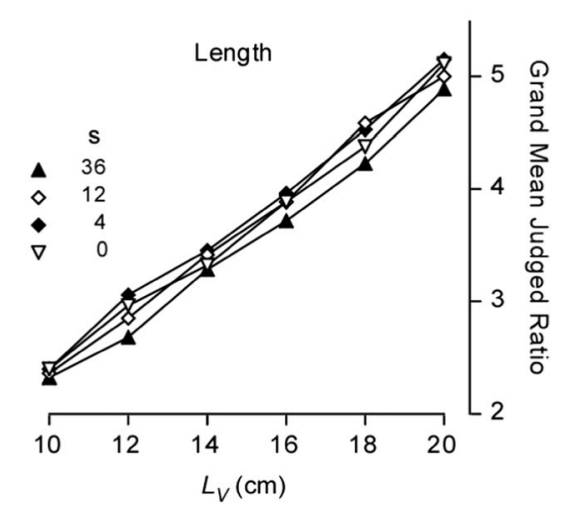

calculated across values of $W_{S}$ and plotted against $W_{V}$ and calculated across values of $L_{S}$ and plotted against $L_{V}$, respectively

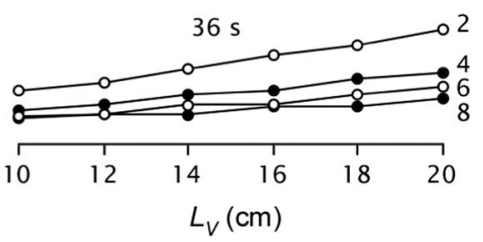




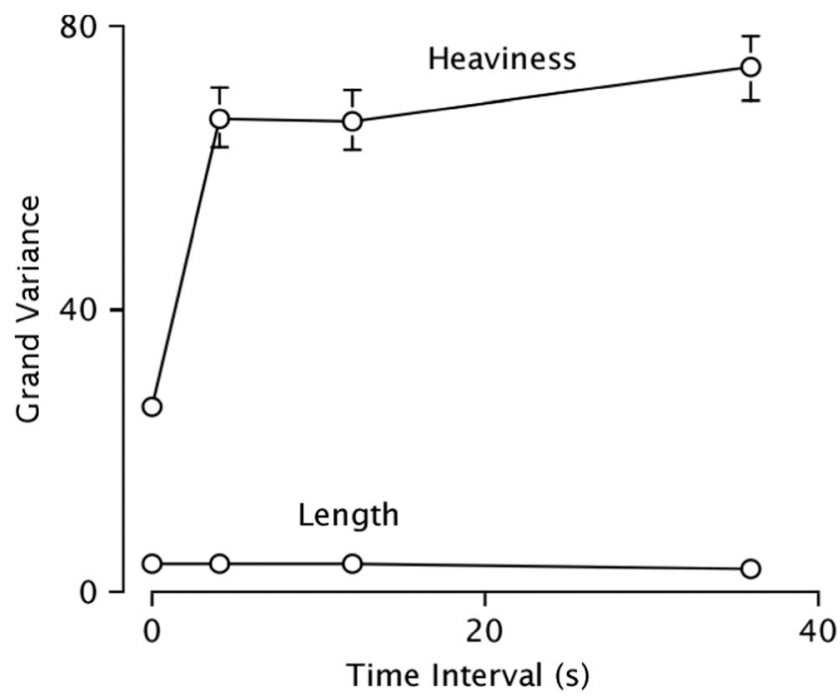

Fig. 4 Grand variances of judgments of heaviness ratios and length ratios, plotted against the time interval. Error bars show standard errors of the grand variances when those are larger than the symbol size

heaviness, the lower variance for the time interval of $0 \mathrm{~s}$ possibly suggests that this judged ratio depended on ongoing or persisting sensory haptic information, whereas the higher variance for longer time intervals possibly suggests that the judged ratios depended on statistically noisier short-term haptic memory information.

\section{Conclusion}

In Fig. 2, for time intervals of 0 and $4 \mathrm{~s}$, judged heaviness ratios and judged length ratios yielded equispaced and hyperbolically spaced factorial curves, respectively. Because the design conditions for these judgments were the same and because people seem to judge length ratios accurately, the different spacings of the factorial curves suggest that participants implemented the instructions to judge heaviness ratios using an operation other than a ratio operation.

Tentatively, one could interpret the results for the time intervals of 0 and $4 \mathrm{~s}$ as follows. People might simulate the judgment of a ratio between heaviness values by judging the heavier heaviness on a bounded scale and varying the upper bound of the scale inversely with the lighter heaviness. This hypothetical operation can be formally described by the multiplication equation

$J=c_{3}+c_{4} \cdot\left(c_{5}-\omega_{S}\right) \cdot \omega_{V}$,

with $c_{3}-c_{5}$ being parameters and $c_{5}>\omega_{S}$ (Masin \& Brancaccio, 2017). With heaviness proportional to weight and equispaced values of $W_{S}$ and $W_{V}$, Eq. 9 implies that the factorial curves relating $J$ to $W_{V}$ form a fan of equispaced straight lines, in agreement with the statistical results for heaviness for the time intervals of 0 and $4 \mathrm{~s}$ in Fig. 2.
For time intervals longer than $4 \mathrm{~s}$, the judged heaviness ratios yielded equispaced parallel factorial curves, possibly indicating a subtractive judgment operation formally described as

$J=c_{6}+c_{7} \cdot\left(\omega_{V}-\omega_{S}\right)$,

with $c_{6}$ and $c_{7}$ being parameters. With heaviness being proportional to weight, Eq. 10 implies that the factorial curves relating $J$ to $W_{V}$ would form a set of parallel straight lines, in accord with the statistical results for heaviness for the time intervals of 12 and $36 \mathrm{~s}$ in Fig. 2.

These results support the indication of Experiment 1 that memory can affect judged sensory ratios. When weights were lifted simultaneously, the judgments resulted from the integration of only haptic sensory information. When weights were lifted successively, the judgments resulted from the integration of haptic sensory information with haptic short-term memory information. One could speculate that the judgments modeled by Eq. 9 would depend on the integration of ongoing or persisting haptic sensory information, and that the judgments modeled by Eq. 10 would depend on the integration of haptic sensory information with haptic short-term memory information. A change in information integration from multiplicative to additive at about $4 \mathrm{~s}$ might be due to some participants being more able than others to counteract the decay of haptic sensory information. More research seems to be needed in order to understand the mechanism that gradually alters the process of information integration from multiplicative to additive, depending on the type of haptic information.

The present results agree with those of Holmin and Norman (2012): The ability of people to judge weight ratios with good accuracy may depend on judgment operations that mimic the ratio operation. Inasmuch as such mimicking operations compensate for the lack of a ratio operation, the resulting judgments might be practically equivalent to those potentially produced by the ratio operation. The near-linear regression between judged heaviness ratios and weight ratios is thus in line with the possibility that people's heaviness judgments are approximations to ratio judgments.

\section{Brightness}

The following results for brightness suggest that an auxiliary operation, formally described by a subtraction operation, may also be generally used to compensate for an inability to judge sensory intensity ratios. For pairs of brightnesses $\beta_{S}$ and $\beta_{V}$ combined factorially, $\beta_{S}<\beta_{V}$, participants were asked to judge the number of times that $\beta_{V}$ was larger than $\beta_{S}$. This judgment can be modeled as

$J=e_{1}+e_{2} \cdot \frac{\beta_{V}}{\beta_{S}}$, 
with $e_{1}$ and $e_{2}$ being parameters. Equation 11 can be reexpressed as

$J \approx e_{1}+e_{3} \cdot \frac{B_{V}}{B_{S}}$,

with $B_{S}$ and $B_{V}$ being the luminances corresponding to $\beta_{S}$ and $\beta_{V}$, respectively, and with $e_{3}$ being a parameter. In Eq. 12 , the approximate equality symbol is used because the psychophysical power function for brightness is curvilinear (Gescheider, 1997; Laming, 1997; Marks, 1974).

Equations 11 and 12 imply that both the factorial curves relating $J$ to $\beta_{V}$ and those relating $J$ to $B_{V}$ would form fanlike patterns. Because Eq. 12 derives from Eq. 11, testing whether the fanlike pattern of factorial curves predicted by Eq. 12 occurs would also be a test of the validity of model Eq. 11 (Anderson, 1974a, 1981, 1982).

Empirically, the factorial curves relating $J$ to $B_{V}$ have been found to be statistically parallel to each other (Masin, 2013, 2014). Because Eq. 12 implies diverging factorial curves, this finding of parallel factorial curves suggests that Eqs. 11 and 12 may be invalid models of ratio judgments. That is, people might not be able to judge brightness ratios.

However, this inability lacks nomothetic validation (Lamiell, 1998; Liew, Howe, \& Little, 2016; Shanteau, 1985; Weiss, 2007). That is, it might be that participants produced different patterns of factorial curves that averaged out to a set of parallel curves, with some participants actually being able to judge brightness ratios.

Supporting this hypothesis, analyses of people's orderings of sensory intensity ratios and sensory intensity differences have indicated that some people respond to both sensory intensity ratios and sensory intensity differences, whereas others respond only to sensory intensity differences (Parker \& Hickman, 1990; Popper, Parker, \& Galanter, 1986; Schneider, 1980; Schneider, Parker, Farrell, \& Kanow, 1976). In line with these findings, Grace, Morton, Ward, Wilson, and Kemp (2018) reported that only half of their participants could be trained with feedback to differentially respond to both brightness ratios and brightness differences. The ability to judge sensory intensity ratios might be confined to individuals who respond to sensory intensity ratios. In Experiment 4 we tested whether participants could judge brightness ratios and whether the potential participants that could make this judgment were the only ones able to respond to brightness ratios.

\section{Experiment 4}

The experiment drew on the ability of people to use their own knowledge of Archimedes' law of the lever to imaginatively "weigh" sensory intensities (Masin, 2016b; Monroe, 1925; Pinkerton \& Humphrey, 1974). Two surfaces were attached to a horizontal line that represented a lever, one with brightness $\beta_{S}$ on the left at a visual distance $\delta_{S}$ from the fulcrum, and one with brightness $\beta_{V}$ on the right at a visual distance $\delta_{V}$ from the fulcrum. Participants were asked to imagine each surface as having a "weight" proportional to its brightness and to position either the fulcrum or the left surface such that the "weights" of the surfaces would keep the lever horizontal.

If people used the knowledge of the law of the lever to perform these tasks, one would find that

$\frac{\delta_{S}}{\delta_{V}}=e_{4} \cdot \frac{\beta_{V}}{\beta_{S}}$

with $e_{4}$ being a proportionality parameter. These tasks imply responding to the ratio $\beta_{V} / \beta_{S}$ nonverbally.

Let $D_{S}$ and $D_{V}$ denote the physical distances, and $B_{S}$ and $B_{V}$ the luminances, corresponding to $\delta_{S}, \delta_{V}, \beta_{S}$, and $\beta_{V}$, respectively. Equation 13 can be reexpressed as

$\frac{D_{S}}{D_{V}} \approx e_{5} \cdot \frac{B_{V}}{B_{S}}$,

with $e_{5}$ being a parameter. The approximation sign is due to brightness varying nonlinearly with luminance.

Equations 13 and 14 imply, respectively, that the factorial curves relating $\delta_{S} / \delta_{V}$ to $\beta_{V}$ and those relating $D_{S} / D_{V}$ to $B_{V}$ would form a fanlike pattern. Because Eq. 14 derives from Eq. 13, testing whether the fanlike factorial pattern predicted by Eq. 14 occurs would be equivalent to testing the model in Eq. 13 (Anderson, 1974a, 1981, 1982).

The same pairs of luminances $B_{S}$ and $B_{V}$ were used for each of four consecutive sessions. The first and fourth sessions assessed whether participants could numerically judge $\beta_{V} / \beta_{S}$. The second and third sessions assessed whether participants could respond nonverbally to $\beta_{V} / \beta_{S}$.

\section{Method}

\section{Participants and stimuli}

Twenty psychology students with a mean age of 21.5 years participated in the experiment. They were tested individually. None had participated in Experiments 1-3.

The experiment took place in a dark room. The stimuli were presented in the middle of a $478 \times 215 \mathrm{~mm}$ black area on a flat display screen. A headrest held the participant's eyes level with each stimulus. The viewing distance was $1 \mathrm{~m}$.

Figure 5 illustrates the stimuli. Each stimulus was a configuration consisting of three $20-\mathrm{mm}$ vertical lines, one 382 $\mathrm{mm}$ horizontal line, and two $35 \times 26 \mathrm{~mm}$ elliptic surfaces. Each line was $0.25 \mathrm{~mm}$ thick. In all trials, the left and right vertical lines were always vertically aligned with the corresponding surface. The symbols $D_{S}$ and $D_{V}$ denote the distances of the central line from the left and right vertical lines. 


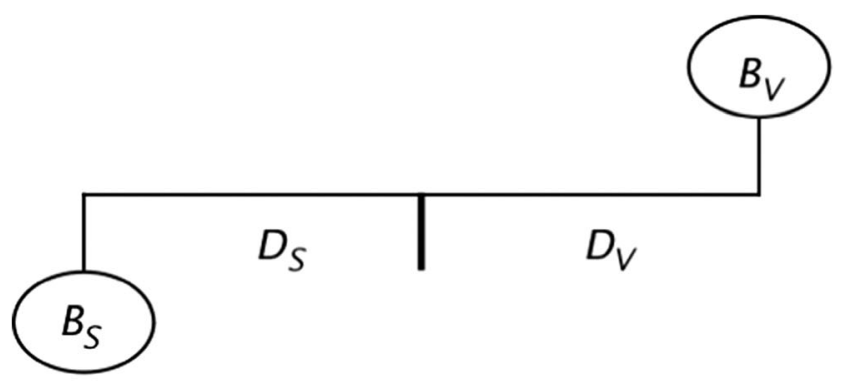

\section{Ratio Judgment (Sessions 1 and 4)}

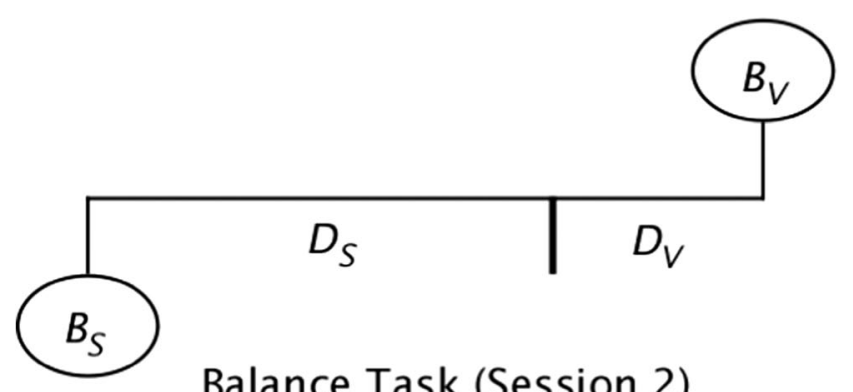

Balance Task (Session 2)

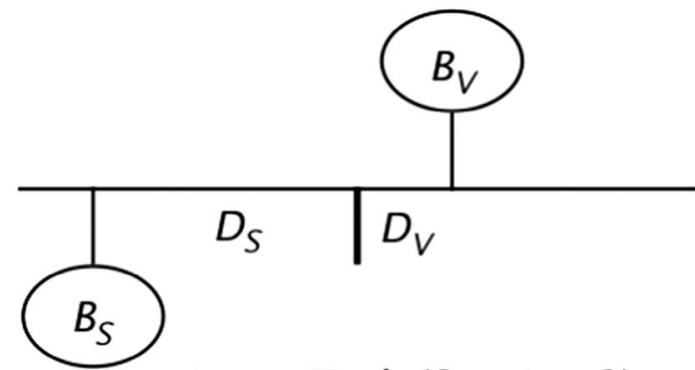

Lever Task (Session 3)

Fig. 5 The configurations made of lines and elliptic surfaces used in Sessions 1-4 of Experiment 4. The surfaces varied in luminance, $B_{S}$ or $B_{V}$. The symbols $D_{S}$ and $D_{V}$ denote the distances of the central vertical line from the left and right vertical lines, respectively. The upper configuration was used for Sessions 1 and 4, in which participants judged the brightness ratio between the surfaces. The central configuration was used for Session 2 , in which participants varied the ratio $D_{S} / D_{V}$ by adjusting the position of the central vertical line. The bottom configuration was used for Session 3 , in which, with $D_{V}$ fixed, the participants varied the ratio $D_{S} / D_{V}$ by adjusting the position of the left surface

All lines were achromatic, except for the middle vertical line, which was colored red (thickened in Fig. 5 for emphasis). The surfaces were also achromatic. The symbols $B_{S}$ and $B_{V}$ denote the luminances of the left and right surfaces, respectively. These luminances were measured by a Konica Minolta CS-200 chroma meter. The background luminance was 0.11 $\mathrm{cd} / \mathrm{m}^{2}$, that of the achromatic lines was $5.6 \mathrm{~cd} / \mathrm{m}^{2}$, and that of the red line was $50 \mathrm{~cd} / \mathrm{m}^{2}$. The luminance $B_{S}$ of the left surface was $0.54,1.13$, or $2.69 \mathrm{~cd} / \mathrm{m}^{2}$, and the luminance $B_{V}$ of the right surface was $5.6,13.7,25.4$, or $53.4 \mathrm{~cd} / \mathrm{m}^{2}$.

Four sessions, Sessions 1, 2, 3, and 4, were conducted in the order from 1 to 4 .

Session 1 used the upper stimulus configuration in Fig. 5 to test whether participants could numerically judge brightness ratios. The red line was centered under the horizontal line.

Session 2 used the middle stimulus configuration in Fig. 5 to test whether participants could nonverbally respond to brightness ratios. Participants here used a computer mouse to move the red line horizontally. They selected a position for the red line under the horizontal line.

Session 3 used the bottom stimulus configuration in Fig. 5 to test again whether participants could nonverbally respond to brightness ratios. In this session, the right surface and right vertical line were displaced such that the lower end of the right vertical line was $20 \mathrm{~mm}$ from the center of the horizontal line. Participants were asked to select a position for the left surface under the horizontal line by synchronously moving the left surface and left vertical line horizontally using a mouse. ${ }^{5}$

A $1,700 \times 750 \mathrm{~mm}$ cardboard sheet was set coplanar with the screen so that the participants could have extra space in case they needed to select a position for the red line that was off the screen. The right side of the cardboard sheet coincided with the left side of the screen. A measuring tape calibrated in millimeters was fastened on the cardboard sheet collinearly with the horizontal line on the screen. The tape's scale was invisible to the participant. If needed, the participant could project a 1-mm-thick steady luminous vertical laser line on the tape using an easily manipulable device.

Session 4 was a repetition of Session 1.

In each session, ten consecutive blocks of 12 randomly ordered trials were presented, with each trial consisting of displaying one stimulus configuration for as long as the participant needed in order to respond. A different factorial combination of $B_{S}$ and $B_{V}$ was used for each trial of a block. The mean duration of the administration of all trials was 10$11 \mathrm{~min}$ in each of Sessions 1-4.

\section{Procedure}

Session 1 Participants were instructed to judge on each trial how many times the right surface was brighter than the left surface. They were asked to verbally express their judgments as decimal numbers, and were given no example of these numerical judgments.

\footnotetext{
${ }^{5}$ Only half of the left surface was visible when the left surface was set all the way to the left with the left vertical line positioned on the left side of the screen. The right surface was drawn above and the left surface below the bar so that these surfaces did not overlap when the left surface was close to the fulcrum.
} 
Session 2 The procedure for Session 2 had three consecutive parts, Parts 1, 2, and 3.

In Part 1, the participant's knowledge was refreshed on Archimedes' equilibrium law for the balance of a lever. For this refreshing, a bar was employed together with two ellipsoidal objects of equal size (hereafter called "objects"). One object was attached to a string, and the other to a thin rod (hereafter called a "prop"). The objects varied in weight. The object with a prop was placed at one end of the bar, with the prop being inserted vertically in a hole in the bar, while the object with a string was hung on the other end of the bar. For different object weights, the participant was asked to select which point on the bar needed to be at the fulcrum in order to keep the bar in horizontal equilibrium. For each weight combination, each participant selected a point on the bar closer to the heavier object.

In Part 2, the participant was then asked to imagine in each stimulus (i) the horizontal line as a bar and the red line as a prop supporting the bar; (ii) the left vertical line as a string attached to the bar, with the left surface hanging from the string; (iii) the right vertical line as a prop resting on the bar, with the right surface laid over the prop; (iv) the left and right surfaces as each having a "weight" proportional to the respective brightnesses; (v) the left surface as pulling down the bar; and (vi) the right surface as pushing down the bar.

In Part 3, for each trial the participant was asked to use a computer mouse to select the position of the red line that would keep the bar horizontal, given the downward forces exerted by the "weights" of the left and right surfaces. The participant clicked a button to end the trial.

Session 3 The procedure for Session 3 also had three successive parts, Parts 1, 2, and 3.

In Part 1, the participant's knowledge of Archimedes' law of the lever was refreshed. Here, the bar's midpoint was set on a fulcrum. An object with a prop was set near the fulcrum, with the prop inserted vertically in a hole in the bar and, and on the opposite side of the fulcrum, an object with a string was hung at the end of the bar. For different object weights, the participant was to find where the object with a string should be hung on the bar in order to keep the bar in horizontal equilibrium. Each participant set the object with a string progressively closer to the fulcrum as the weight of the object with a prop increased.

In Part 2, the participant was then asked to imagine each stimulus of Session 3 in the same manner specified in Part 2 of Session 2.

In Part 3, the participant was instructed to select on each trial the position of the left vertical line that would keep the bar horizontal, given the "weights" of the left and right surfaces. To do this, participants synchronously moved the left surface and the attached vertical line using a computer mouse. They were told that, if they thought the bar was too short to allow for horizontal equilibrium, they could select a potential position of the left vertical line on the screen between the bar and the left side of the screen or, alternatively, on the tape on the cardboard sheet by projecting a vertical laser line. Participants ended the trial by clicking a mouse button after they had selected a position of the left vertical line on the screen. After a participant had indicated a position of the left vertical line on the cardboard sheet, the experimenter read the distance $D_{S}$ on the measuring tape fastened on the cardboard sheet and ended the trial by typing the reading into the computer.

In Session 3, the data for one participant were accidentally lost. Six of the participants always set the left vertical line on the bar (three of them positioned it one to five times at the bar's left end), and 13 selected 2-30 times a position of the left vertical line between the fulcrum and the screen's left side (five of them positioned it on the screen's left side one to six times). Using the laser line, four of these 13 participants selected a position for the red line on the cardboard sheet one or two times, at a distance $5-54 \mathrm{~mm}$ from the screen.

Session 4 The procedure for Session 4 was the same as that for Session 1.

\section{Results and discussion}

A $3\left(B_{S}\right) \times 4\left(B_{V}\right)$ ANOVA was carried out for each participant and session using a .05 level of statistical significance. The scores for these ANOVAs were ratio judgments for Sessions 1 and 4 , and ratios $D_{S} / D_{V}$ for Sessions 2 and 3 (Eq. 14).

Table 1 shows the results for each participant and session. Participants were sorted in order to improve legibility, and then were numbered. One cell is blank due to a loss of data. The symbols have the following meanings: "=," statistically parallel factorial curves; "<" and ">," significant rightward divergence and convergence of the factorial curves, respectively; " $\times$," a significant interaction, with no clear global convergence or divergence of factorial curves.

\section{Results of Session 1}

Statistically, the factorial curves relating $J$ to $B_{V}$ were parallel for 17 participants, converged rightward for two, and were not parallel and globally not diverging or converging for one. These results suggest that none of the participants could judge brightness ratios.

\section{Results of Sessions 2 and 3}

At least in one session, the factorial curves statistically relating $D_{S} / D_{V}$ to $B_{V}$ were parallel for 13 participants, diverged rightward for 11, and were not parallel and globally not diverging or converging for two. These results suggest the ability of 11 participants to respond nonverbally to brightness ratios. 
Table 1 Results of Experiment 4

\begin{tabular}{|c|c|c|c|c|}
\hline Participant & Session 1 (Ratio Judgment) & Session 2 (Balance Task) & Session 3 (Lever Task) & Session 4 (Ratio Judgment) \\
\hline 1 & $=$ & $=$ & $=$ & $=$ \\
\hline 2 & $=$ & $=$ & $=$ & $=$ \\
\hline 3 & $=$ & $=$ & $=$ & $=$ \\
\hline 4 & $=$ & $=$ & $=$ & $=$ \\
\hline 5 & $=$ & $=$ & & $=$ \\
\hline 6 & $=$ & $=$ & $=$ & $x$ \\
\hline 7 & $>$ & $=$ & $=$ & $>$ \\
\hline 8 & $\times$ & $\times$ & $\times$ & $=$ \\
\hline 9 & $>$ & $\times$ & $<$ & $\times$ \\
\hline 10 & $=$ & $<$ & $=$ & $=$ \\
\hline 11 & $=$ & $<$ & $=$ & $=$ \\
\hline 12 & $=$ & $<$ & $=$ & $=$ \\
\hline 13 & $=$ & $=$ & $<$ & $=$ \\
\hline 14 & $=$ & $<$ & $<$ & $=$ \\
\hline 15 & $=$ & $<$ & $<$ & $=$ \\
\hline 16 & $=$ & $<$ & $<$ & $=$ \\
\hline 17 & $=$ & $<$ & $<$ & $>$ \\
\hline 18 & $=$ & $<$ & $<$ & $<$ \\
\hline 19 & $=$ & $=$ & $<$ & $<$ \\
\hline 20 & $=$ & $=$ & $=$ & $<$ \\
\hline
\end{tabular}

The symbols mean that, statistically, the factorial curves were parallel (=), diverged rightward $(<)$, converged rightward $(>)$, or did not globally either converge or diverge $(\times)$. One table cell is blank due to a loss of data

\section{Results of Session 4}

Statistically, the factorial curves relating $J$ to $B_{V}$ were parallel for 13 participants, converged rightward for two, diverged rightward for three, and were not parallel and globally not converging or diverging for two. Thus, the participants who had shown an inability to respond nonverbally to brightness ratios, as well as most of those who seemed to be able, showed an inability to judge brightness ratios in Session 4.

Figure 6 shows examples of the participants' mean responses (either judged ratios or $D_{S} / D_{V}$ ratios), plotted against the luminance of the right surface, $B_{V}$, for each luminance of the left surface, $B_{S}$. The rows of diagrams show the results for Participants 3, 9, and 16, and the columns for Sessions 1, 2, 3, and 4 . Participant 3 yielded nonsignificant interactions, $F(6$, $54)<1, F(6,54)=1.7, F(6,54)<1$, and $F(6,54)=1.3$ for Sessions $1-4$, respectively, whereas Participant 9 yielded significant interactions, $F(6,54)=3.0\left(\eta_{\mathrm{p}}{ }^{2}=.25\right), F(6,54)=2.9$ $\left(\eta_{\mathrm{p}}{ }^{2}=.25\right), F(6,54)=3.2\left(\eta_{\mathrm{p}}{ }^{2}=.35\right)$, and $F(6,54)=2.5\left(\eta_{\mathrm{p}}{ }^{2}=\right.$ $.21), p s<.5$, respectively. Participant 16 yielded nonsignificant interactions in Sessions 1 and $4, F(6,54)<1$ and $F(6,54)$ $=1.4$, and significant interactions in Sessions 2 and $3, F(6,54)$ $=3.9\left(\eta_{\mathrm{p}}{ }^{2}=.30\right)$ and $F(6,54)=4.8\left(\eta_{\mathrm{p}}{ }^{2}=.26\right), p \mathrm{~s}<.005$, respectively.

\section{Cautionary remarks}

In the stimuli, the division of the horizontal bar by the vertical lines could have altered $\delta_{S}$ and $\delta_{V}$ (Robinson, 1998). This effect, however, does not seem to occur under prolonged observation (Lewis, 1912). In Experiment 2, bar divisions might have affected $\delta_{S}$ and $\delta_{V}$ minimally, due to prolonged viewing.

Surfaces may change in brightness with their reciprocal distance (Leibowitz, Mote, \& Thurlow, 1953). The intersurface distance may thus have influenced $\beta_{S}$ and $\beta_{V}$. This influence seems to have been negligible for the stimulus conditions of Experiment 4, given that the experimenter did not detect it even under careful inspection, and that no participant reported having noticed it.

In actual balance scales or actual levers, all weights are typically set either below or above the beam. To avoid superimposition of the surfaces near the fulcrum, in each experimental stimulus of Experiment 4, one surface was presented below the horizontal line, and one above. Could such an unusual mode of presentation of the surfaces have adversely affected participants' responses? Preexperimentally, each participant had interacted with an actual beam with one weight below 

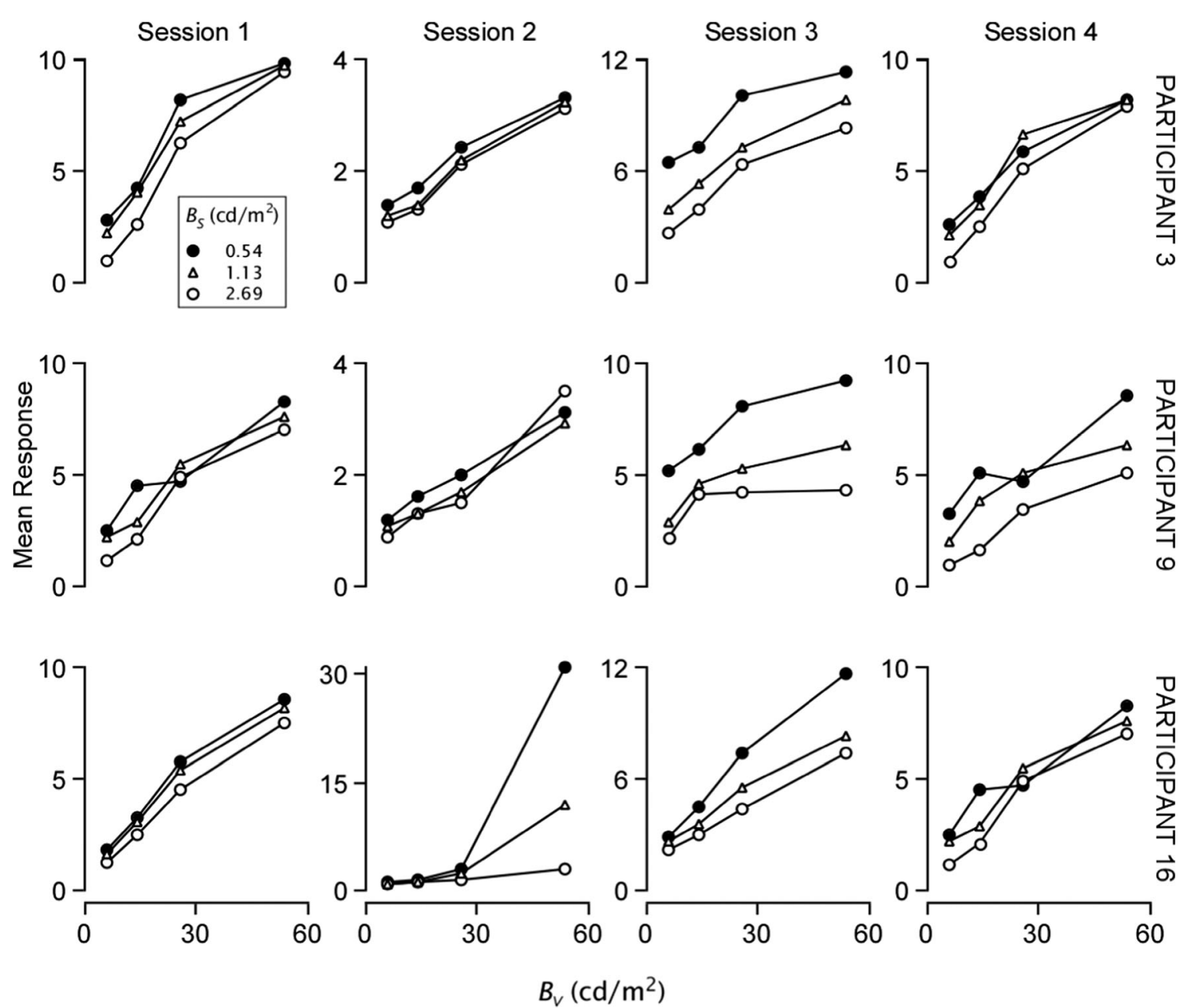

Fig. 6 Examples of individual results from Experiment 4. Mean responses - either judged ratios in Sessions 1 and 4 or $D_{S} / D_{V}$ ratios in Sessions 2 and 3 - as a function of the luminance of the right surface, $B_{V}$,

for each luminance of the left surface, $B_{S}$, for Participants 3, 9, and 16. The lack of rightward divergence of the curves suggests a lack of ability to judge or to respond to the ratios

and one above the beam, and each participant indicated where the fulcrum and the weights were to be positioned in order to keep the beam in horizontal equilibrium. Since every participant manifested correct intuitive knowledge of the physical law of the lever during this practice with an unusual mode of presentation of the weights, the unusual mode of presentation of the surfaces in the experimental stimuli may have had negligible or no adverse effect on participants' responses.

\section{Conclusion}

The results from Session 1 support the hypothesis that people cannot judge brightness ratios, both as a group and individually.

The equation

$J=e_{6}+e_{7} \cdot\left(\beta_{V}-\beta_{S}\right)$,

with $e_{6}$ and $e_{7}$ being parameters, implies that the factorial curves relating $J$ to $\beta_{V}$ for each $\beta_{S}$ are parallel straight lines
(Anderson, 1981, 1982). In conformity with Eq. 15, for 17 participants the factorial curves relating $J$ to $B_{V}$ formed a set of statistically parallel curves (Table 1$)^{6}$

Most participants did not judge brightness ratios even when some of them seemed able to respond nonverbally to brightness ratios. Only Participants 18 and 19 seemed able to judged brightness ratios after responding nonverbally to brightness ratios. They might have developed a mental model of the lever in Sessions 2 and 3 and used it in Session 4. Because Eqs. 12 and 14 are approximate models, one cannot know whether the participants who seemed able to judge ratios had judged ratios

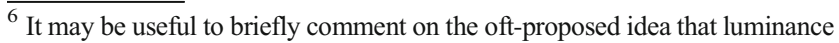
ratios determine the lightness or brightness of surfaces (Gilchrist, 1994, 2006). On the basis of this idea, one might conjecture that the brightnesses in Eq. 11 should be substituted for with their corresponding luminances. Equation 11 with luminances in place of brightnesses still predicts diverging factorial curves. The finding of parallel factorial curves suggests that participants did not judge brightness ratios, nor did they judge luminance ratios in the task of numerically expressing brightness ratios.
} 
accurately and whether those who seemed able to respond to ratios were responding to the actual ratios.

Equation 15 has implications for the scaling of brightness. The parallelism theorem of integration psychophysics shows that model Eq. 15 implies that the column marginal means of the factorial design, $\bar{J}$, are measures of $\beta_{V}$ on a linear interval scale (Anderson, 1982, p. 58). That is,

$\bar{J}=e_{8}+e_{9} \cdot \beta_{V}$,

with $e_{8}$ and $e_{9}$ being parameters.

Assuming that the psychophysical function for brightness is the power function $\beta_{V}=k \cdot B_{V}^{n}$, Eq. 16 is equivalent to

$\bar{J}=e_{8}+e_{10} \cdot B_{V}^{n}$,

with $B_{V}$ being the luminance corresponding to $\beta_{V}, n$ the exponent for brightness, and $k$ and $e_{10}$ parameters.

We calculated the values of $\bar{J}$ for the group of 12 participants who produced statistically parallel factorial curves in both Sessions 1 and 4 of Experiment 4 . These values increased with stimulus luminance, and were 1.7, 2.73, 4.22, and 5.66 in Session 1, and 1.63, 2.42, 3.49, and 4.65 in Session 4. Leastsquares fits of Eq. 17 to these data yielded the estimated exponents $0.31\left(e_{8}=-2.37, e_{10}=2.34\right)$ for Session 1 and 0.35 $\left(e_{8}=-1.01, e_{10}=1.43\right)$ for Session 4.

Figure 7 shows the mean $\bar{J}$ values for each stimulus luminance. The curve in this figure represents a least-squares fit of Eq. 17 to the data. This fit yielded the estimated power exponent 0.33 .

\section{General discussion}

In this study we investigated whether people are able to judge sensory ratios. Participants were asked to numerically judge

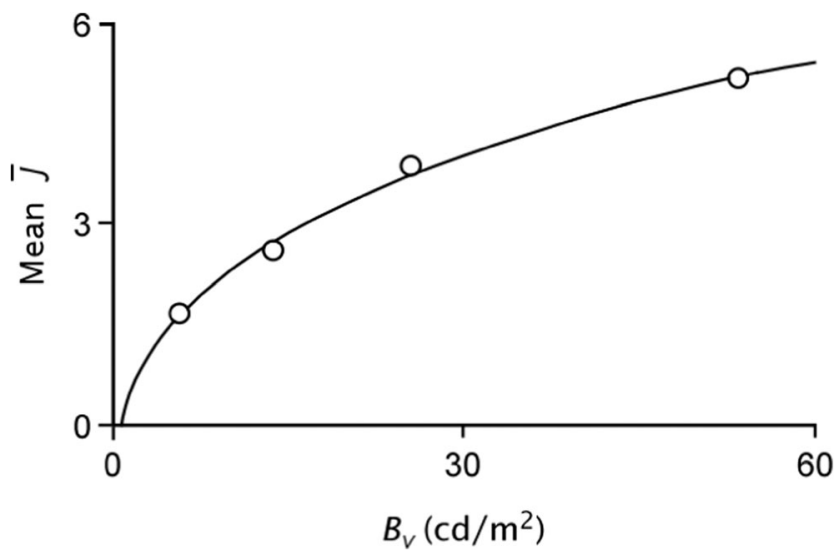

Fig. 7 Illustration of the psychophysical power function for brightness with an exponent of 0.33 , for mean judged ratios of brightness, $\bar{J}$, plotted against luminance, $B_{V}$ ratios of extensive magnitude (frontal linear length) or intensive magnitude (either heaviness of lifted weights or surface brightness). A model of ratio judgment fit the judged length ratios accurately (Exps. 1 and 3 ) and fit the judged heaviness ratios (Exp. 2) and judged brightness ratios (Exp. 4) inaccurately. These findings suggest that people can judge ratios of extensive sensory magnitude, but not ratios of intensive sensory magnitude.

Judged heaviness ratios were inaccurate, but only slightly so. The present findings that the participants judged length ratios accurately and heaviness ratios nearly accurately conform with those of the correlational studies performed by Norman et al. (2017) and Holmin and Norman (2012), which were, respectively, conducted on ratios of perceived distance and ratios of the heaviness of lifted weights. Additionally, the present results show that most participants inaccurately judged ratios of perceived brightness, and that such inaccuracy was very large.

The patterns of empirical factorial curves obtained for brightness suggest that participants carried out the task of judging brightness ratios by using a subtraction operation. The robustness of this finding was supported by the further finding that a substantial number of participants were still not able to judge brightness ratios after they appeared to be able to respond to brightness ratios in a perceptual/cognitive task in which they had to use their own knowledge of the law of the lever. A reason why people appear to be accurate or nearly accurate in judging length ratios and heaviness ratios, while they are largely inaccurate in judging brightness ratios, may be that they can often receive numerical feedback about physical ratios when they judge ratios of perceived length or ratios of perceived heaviness, whereas they can rarely or never receive numerical feedback about physical ratios when they judge ratios of perceived brightness.

\section{Ordinal tests and integration psychophysics}

Psychophysicists have used ordinal tests to verify whether people can numerically judge sensory ratios. These ordinal tests unanimously suggest that people judge sensory ratios inaccurately, but they leave unanswered why such inaccuracy occurs. That is, these tests are mute as to whether people may use nonratio operations to compensate for the inability to judge ratios. To attempt to overcome these limitations, we used the approach of integration psychophysics to explore which nonratio judgment operations might account for people's potential inability to judge sensory ratios. This approach is based on the application of experimental factorial designs. The resulting patterns of factorial curves can simultaneously reveal both whether participants are able to judge ratios and which nonratio operation might be alternatively used, in the event of a lack of ability to judge ratios. 


\section{Auxiliary nonratio judgment operations}

Length People's ability to judge ratios of length does not necessarily entail that their judgment system is equipped with a mechanism capable of directly converting ratios of sensory length into numerical responses. That such a mechanism does not plausibly exist is indicated by Hartley's $(1977,1981)$ finding that people carry out the task of numerically judging the ratio between the length of a test line and that of a shorter standard line by quickly counting mentally how many times the standard line is contained in the test line. The time required to judge this ratio increases linearly with the length of the test line and as the length of the standard line decreases. These findings support the idea that people judge length ratios by mentally concatenating the standard line with itself along the test line. Each step of such concatenation takes time. For example, it normally takes about $1.5 \mathrm{~s}$ to report a length ratio of $1: 3$, and about $2.5 \mathrm{~s}$ to report a ratio of 1:8 (Masin, 2013). If we were equipped with a neural mechanism that directly converted ratios of sensory length into numerical responses, all judgments of ratios should instead take the same time. To compensate for the lack of such a mechanism, we use the auxiliary nonratio operation of mental counting.

Heaviness That people may also use auxiliary nonratio judgment operations to compensate for inability to judge intensity ratios is suggested by a comparison of judgments of length ratios with judgments of heaviness ratios under the same experimental design conditions (Exps. 2 and 3). The factorial results for length conformed with a ratio operation whereas those for heaviness did not. For heaviness, the results suggest people's use of two auxiliary nonratio operations depending on the time interval between two successively lifted weights. For short time intervals, factorial curves diverged from each other as would be expected from a ratio operation. However, the type of factorial curve spacing failed to indicate a ratio operation, given that a ratio operation implies hyperbolically spaced factorial curves, whereas the empirically obtained factorial curves turned out to be statistically equispaced. Such equispacing of factorial curves suggests that participants used a judgment operation formally equivalent to a multiplication. A multiplicative factorial pattern could occur if participants use a category scale with variable bounds. For relatively long time intervals, factorial curves were found instead to be statistically parallel to each other as would be expected from a subtraction operation. Thus, under the task of judging heaviness ratios, people appear to either categorize heaviness values or judge heaviness differences.

Brightness The use of an auxiliary nonratio judgment operation to compensate for an inability to judge ratios was also found for the sensory dimension of brightness. Such a nonratio operation was deduced from the parallelism of empirically obtained factorial curves. Given that the ability to judge sensory ratios implies diverging factorial curves, the finding of this parallelism further supports that people lack a mechanism that converts sensory intensity ratios into numerical responses.

This inability conforms to the finding that people seem unable to use mental counting for judging brightness ratios. That is, the time required to numerically judge the ratio between two brightness values seems to be independent of the ratio between these values. For example, unlike with judgments of length ratios, it takes about $1.5 \mathrm{~s}$ both to report a brightness ratio of $1: 3$ and to report one of 1:8 (Masin, 2013).

Parallelism of factorial curves thus suggests that people use an auxiliary nonratio operation formally equivalent to a subtraction operation to compensate for their inability to directly convert brightness ratios into numerical responses. This subtraction operation suggests that people might try to carry out the task of judging brightness ratios by judging brightness differences.

\section{Sensory scaling}

The assumed ability for people to judge sensory ratios is used to determine sensory scales. Do the judgment operations that compensate for the lack of this ability allow for sensory scaling? The present results suggest an affirmative answer, because Equations 6, 9, 10, and 15 express that numerical judgments are linear interval-scale measures of length, heaviness, and brightness, corresponding to each fixed value of $\lambda_{S}, \omega_{S}$, and $\beta_{S}$, respectively. The present linear measures of length and heaviness are of scarce interest for scaling, because they refer to narrow stimulus ranges for which the respective psychophysical functions are practically linear, independent of the size of the exponent. The present linear measures of brightness refer instead to a substantially wider stimulus range, and could thus be used to determine the exponent of the psychophysical power function.

The mean exponent estimated for this function was 0.33 . This coincidentally happens to be the same brightness exponent that was obtained using the magnitude estimation method under dark-adapted viewing conditions (S. S. Stevens \& Galanter, 1957). Since magnitude estimation requires participants to judge ratios, a brightness exponent of 0.33 obtained by this method is assumed to describe judgments of ratios (S. S. Stevens, 1975; Teghtsoonian, 2012; Zwislocki, 2009). However, this assumption lacks clear empirical support (Laming, 1997, p. 91). On the other hand, the derivation of Eq. 17 from the subtraction Eq. 15 and the fact that Eq. 17 fits the data for an exponent of 0.33 jointly support the hypothesis that at least the majority of people may judge brightness differences when they carry out the task of judging brightness ratios. 
Author note We gratefully thank Norman Anderson, Armando Oliveira, Loes van Dam, David Weiss, and two anonymous reviewers for important feedback on earlier drafts of this article. A portion of the present results was presented at the Sixth Information Integration Theory and Functional Measurement Conference, Montreal, Canada, June 14-16, 2017, and another portion was presented in Andrea Tomassetti's undergraduate dissertation thesis "Experimental Comparison of Judgments of Quantitative Ratios of Subjective Heaviness and Subjective Length," Department of General Psychology, University of Padua, Italy, 2017.

\section{References}

Algom, D., \& Cohen-Raz, L. (1984). Visual velocity input-output functions: The integration of distance and duration onto subjective velocity. Journal of Experimental Psychology: Human Perception and Performance, 10, 486-501.

Algom, D., \& Cohen-Raz, L. (1987). Sensory and cognitive factors in the processing of visual velocity. Journal of Experimental Psychology: Human Perception and Performance, 13, 3-13. https://doi.org/10. 1037/0096-1523.13.1.3

Algom, D., Wolf, Y., \& Bergman, B. (1985). Integration of stimulus dimensions in perception and memory: Composition rules and psychophysical relations. Journal of Experimental Psychology: General, 114, 451-471. https://doi.org/10.1037/0096-3445.114.4.451

Anderson, N. H. (1974a). Algebraic models in perception. In E. C. Carterette \& M. P. Friedman (Eds.), Handbook of perception (Vol. 2, pp. 215-298). New York, NY: Academic Press.

Anderson, N. H. (1974b). Cross-task validation of functional measurement using judgments of total magnitude. Journal of Experimental Psychology, 102, 226-233.

Anderson, N. H. (1981). Foundation of information integration theory. New York, NY: Academic Press.

Anderson, N. H. (1982). Methods of information integration theory. New York, NY: Academic Press.

Anderson, N. H. (1983). Cognitive algebra in intuitive physics. In H.-G. Geissler, H. F. J. M. Buffart, E. L. J. Leeuwenberg, \& V. Sarris (Eds.), Modern issues in perception (pp. 229-253). Amsterdam, The Netherlands: North-Holland.

Anderson, N. H. (1990). Integration psychophysics. In H.-G. Geissler (Ed.), Psychophysical explorations of mental structures (pp. 7193). Lewiston, NY: Hogrefe \& Huber.

Anderson, N. H. (1992). Integration psychophysics and cognition. In D. Algom (ed.), Psychophysical approaches to cognition (pp. 13-113). Amsterdam, The Netherlands: North-Holland.

Anderson, N. H. (1996). A functional theory of cognition. Hillsdale, NJ: Erlbaum.

Anderson, N. H. (2008). Unified social cognition. New York, NY: Psychology Press.

Anderson, N. H., \& Weiss, D. J. (1971). Test of a multiplying model for estimated area of rectangles. American Journal of Psychology, 84, 543-548.

Augustin, T. (2010). Extensions of Narens' theory of ratio magnitude estimation. British Journal of Mathematical and Statistical Psychology, 63, 647-663.

Augustin, T., \& Maier, K. (2008). Empirical evaluation of the axioms of multiplicativity, commutativity, and monotonicity in ratio production of area. Acta Psychologica, 129, 208-216.

Baird, J. C. (1970). Psychophysical analysis of visual space. Oxford, UK: Pergamon Press.

Bogartz, R. S. (1979). Line ratio judgments yield subjective lengths proportional to physical lengths: Reanalysis of Engen's data. Perception \& Psychophysics, 26, 247-249.

Collyer, C. E. (1985). Comparing strong and weak models by fitting them to computer-generated data. Perception \& Psychophysics, 38, 476-481.
Collyer, C. E. (1988). Parameter estimates depend both on the source model and on the fitted model: An example. Bulletin of the Psychonomic Society, 26, 289-292.

De Sá Teixeira, N. A., Oliveira, A. M., \& Silva, A. D. (2014). An information integration study on the intuitive physics of the Newton's cradle. Psicológica, 35, 479-502.

Ellermeier, W., \& Faulhammer, G. (2000). Empirical evaluation of axioms fundamental to Stevens's ratio-scaling approach: I. Loudness production. Perception \& Psychophysics, 62, 1505-1511. https:// doi.org/10.3758/BF03212151

Fagot, R. F., \& Stewart, M. (1969). Tests of product and additive scaling axioms. Perception \& Psychophysics, 5, 117-123. https://doi.org/ 10.3758/BF03210534

Faleiros Sousa, F. A. E., \& Hortense, P. (2006). Social perception of nursing professional assessed by different scales. Revista LatinoAmericana de Enfermagem, 14, 857-862.

Fechner, G. T. (1887). Über die psychischen Massprincipien und das Weber'sche Gesetz. Philosophische Studien, 4, 161-230.

Geiger, P. H., \& Firestone, F. A. (1933). The estimation of fractional loudness. Journal of the Acoustical Society of America, 5, 25-30.

Gescheider, G. A. (1997). Psychophysics: The fundamentals. Mahwah, NJ: Erlbaum.

Gilchrist, A. (1994). Introduction: Absolute versus relative theories of lightness perception. In A. Gilchrist (Ed.), Lightness, brightness and transparency (pp. 1-34). Hillsdale, NJ: Erlbaum.

Gilchrist, A. (2006). Seeing black and white. New York, NY: Oxford University Press.

Grace, R. C., Morton, N. J., Ward, M. D., Wilson, A. J., \& Kemp, S. (2018). Ratios and differences in perceptual comparison: A reexamination of Torgerson's conjecture. Journal of Mathematical Psychology, 85, 62-75.

Greenwald, A. G. (1976). Within-subjects designs: To use or not to use? Psychological Bulletin, 83, 314-320. https://doi.org/10.1037/00332909.83.2.314

Grice, G. R. (1966). Dependence of empirical laws upon the source of experimental variation. Psychological Bulletin, 66, 488-498.

Ham, L. B., \& Parkinson, J. S. (1932). Loudness and intensity relations. Journal of the Acoustical Society of America, 3, 511-534.

Hartley, A. A. (1977). Mental measurement in the magnitude estimation of length. Journal of Experimental Psychology: Human Perception and Performance, 3, 622-628. https://doi.org/10.1037/0096-1523. 3.4.622

Hartley, A. A. (1981). Mental measurement of line length: The role of the standard. Journal of Experimental Psychology: Human Perception and Performance, 7, 309-317. https://doi.org/10.1037/0096-1523. 7.2.309

Holmin, J. S., \& Norman, J. F. (2012). Aging and weight-ratio perception. PLoS ONE, 7, e47701. https://doi.org/10.1371/journal.pone. 0047701

Hubbard, T. L. (1994). Memory psychophysics. Psychological Research, $56,237-250$.

Hubbard, T. L., \& Baird, J. C. (1988). Overflow, first-sight, and vanishing point distances in visual imagery. Journal of Experimental Psychology: Learning, Memory, and Cognition, 14, 641-649. https://doi.org/10.1037/0278-7393.14.4.641

James, W. (1890). The principles of psychology (Vol. 1). New York, NY: Henry Holt.

Kemp, S. (1988). Memorial psychophysics for visual area: The effect of retention interval. Memory \& Cognition, 16, 431-436. https://doi. org/10.3758/BF03214223

Kerst, S. M., Howard, J. H., \& Gugerty, L. J. (1987). Judgment accuracy in pair-distance estimation and map sketching. Bulletin of the Psychonomic Society, 25, 185-188.

Kiphart, M. J., Hughes, J. L., Simmons, J. P., \& Cross, H. A. (1992). Short-term haptic memory for complex objects. Bulletin of the Psychonomic Society, 30, 212-214. 
Krantz, D. H. (1972). Visual scaling. In D. Jameson \& L. M. Hurvich (Eds.), Visual Psychophysics (pp. 660-689). Berlin, Germany: Springer.

Krist, H., Fieberg, E. L., \& Wilkening, F. (1993). Intuitive physics in action and judgment: The development of knowledge about projectile motion. Journal of Experimental Psychology: Learning, Memory, and Cognition, 19, 952-966. https://doi.org/10.1037/ 0278-7393.19.4.952

Laird, D. A., Taylor, E., \& Wille, H. H., Jr. (1932). The apparent reduction of loudness. Journal of the Acoustical Society of America, 3, 393401. https://doi.org/10.1121/1.1915570

Lamiell, J. T. (1998). "Nomothetic" and "idiographic": Contrasting Windelband's understanding with contemporary usage. Theory and Psychology, 8, 23-38.

Laming, D. (1997). The measurement of sensation. Oxford, UK: Oxford University Press.

Lanca, M., \& Bryant, D. (2001). Euclidean metric representations of haptically explored triangles. American Journal of Psychology, 114, 377-409.

Lawless, H. T., \& Heymann, H. (2010). Sensory evaluation of food: Principles and practices. New York, NY: Springer.

Leibowitz, H., Mote, F. A., \& Thurlow, W. R. (1953). Simultaneous contrast as a function of separation between test and inducing fields. Journal of Experimental Psychology, 46, 453-456.

Lewis, E. O. (1912). The illusion of filled and unfilled space. British Journal of Psychology, 5, 36-50.

Liew, S. X., Howe, P. D. L., \& Little, D. R. (2016). The appropriacy of averaging in the study of context effects. Psychonomic Bulletin \& Review, 23, 1639-1646.

Lim, J. (2011). Hedonic scaling: A review of methods and theory. Food Quality and Preference 22, 733-747.

Luce, R. D. (2012). Torgerson's conjecture and Luce's magnitude production representation imply an empirically false property. Journal of Mathematical Psychology, 56, 176-178.

Marks, L. E. (1974). Sensory processes: The new psychophysics. New York, NY: Academic Press.

Marks, L. E., \& Cain, W. S. (1972). Perception of intervals and magnitudes for three prothetic continua. Journal of Experimental Psychology, 94, 6-17.

Masin, S. C. (2008). Is self-estimated linear length linear? In B. A. Schneider, B. M. Ben-David, S. Parker, \& W. Wong (Eds.), Proceedings of the Twenty-Fourth Annual Meeting of the International Society for Psychophysics (pp. 265-270). Toronto, ON, Canada: International Society for Psychophysics.

Masin, S. C. (2013). On the ability to directly evaluate sensory ratios. Attention, Perception, \& Psychophysics, 75, 194-204. https://doi. org/10.3758/s13414-012-0382-0

Masin, S. C. (2014). Test of the ratio judgment hypothesis. Journal of General Psychology, 141, 130-150.

Masin, S. C. (2016a). The cognitive and perceptual laws of the inclined plane. American Journal of Psychology, 129, 221-234.

Masin, S. C. (2016b). The weight of light. Universitas Psychologica, 15, $1-6$.

Masin, S. C., \& Agostini, A. (1990). Time errors in the method of pair comparisons. American Journal of Psychology, 103, 487-494.

Masin, S. C., \& Agostini, A. (1991). Attentional scanning and space errors. Perception \& Psychophysics, 50, 285-289.

Masin, S. C., \& Anali, D. (2011). Simultaneous use of different mental standards in magnitude estimation of line length. In D. Algom, D. Zakay, E. Chajut, S. Shaki, Y. Mama, \& V. Shakuf (Eds.), Proceedings of the Twenty-Seventh Annual Meeting of the International Society for Psychophysics (pp. 233-238). Raanana, Israel: International Society for Psychophysics.

Masin, S. C., \& Brancaccio, A. (2017). Judgments of differences and ratios of subjective heaviness. Attention, Perception, \&
Psychophysics, 79, 1860-1869. https://doi.org/10.3758/s13414017-1334-5

McBride, R. L. (1993). Integration psychophysics: The use of functional measurement in the study of mixtures. Chemical Senses, 18, 83-92.

McBride, R. L., \& Anderson, N. H. (2014). Integration psychophysics in the chemical senses. In N. H. Anderson (Ed.), Contributions to information integration theory. Vol. 1: Cognition (pp. 295-319). New York, NY: Psychology Press.

Merkel, J. (1888). Die Abhängigkeit zwischen Reiz und Empfindung. Philosophische Studien, 4, 541-594.

Monroe, M. (1925). The apparent weight of color and correlated phenomena. American Journal of Psychology, 26, 192-206.

Mullet, E., \& Chasseigne, G. (2018). Assessing information integration processes: A comparison of findings obtained with between-subjects designs versus within-subjects designs. Quality and Quantity, 52, 1977-1988.

Myung, I. J. (2000). The importance of complexity in model selection. Journal of Mathematical Psychology, 44, 190-204. https://doi.org/ 10.1006/jmps.1999.1283

Norman, J. F., Adkins, O. C., Dowell, C. J., Shain, L. M., Hoyng, S. C., \& Kinnard, J. D. (2017). The visual perception of distance ratios outdoors. Attention, Perception, \& Psychophysics, 79, 1195-1203. https://doi.org/10.3758/s13414-017-1294-9

Norman, J. F., Adkins, O. C., \& Pedersen, L. E. (2016). The visual perception of distance ratios in physical space. Vision Research, 123, 1-7. https://doi.org/10.1016/j.visres.2016.03.009

Parker, S., \& Hickman, D. (1990). Heaviness ratio estimates follow weight ratios for some subjects. In F. Müller (Ed.), Proceedings of the Sixth Annual Meeting of the International Society for Psychophysics (pp. 100-105). Würzburg, Germany: International Society for Psychophysics.

Pinkerton, E., \& Humphrey, N. K. (1974). The apparent heaviness of colours. Nature, 250, 164-165.

Popper, R., Parker, S., \& Galanter, E. (1986). Dual loudness scales in individual subjects. Journal of Experimental Psychology: Human Perception and Performance, 12, 61-69. https://doi.org/10.1037/ 0096-1523.12.1.61

Rahe, R. H., Veach, T. L., Tolles, R. L., \& Murakami, K. (2000). The stress and coping inventory: An educational and research instrument. Stress Medicine, 16, 199-208.

Reed, S. K., Hock, H. S., \& Lockhead, G. (1983). Tacit knowledge and the effect of pattern recognition on mental scanning. Memory \& Cognition, 11, 137-143.

Richardson, L. F. (1929). Quantitative mental estimates of light and colour. British Journal of Psychology, 20, 27-37.

Robinson, J. O. (1998). The psychology of visual illusion. Mineola, NY: Dover.

Rossi, G. B., \& Berglund, B. (2011). Measurement involving human perception and interpretation. Measurement, 44, 815-822.

Ruskin, D., Amaria, K. A., Warnock, F. F., \& McGrath, P. A. (2011). Assessment of pain in infants, children, and adolescents. In D. C. Turk \& R. Melzack (Eds.), Handbook of pain assessment (pp. 213-241). New York, NY: Guilford Press.

Schneider, B. (1980). A technique for the nonmetric analysis of paired comparisons of psychological intervals. Psychometrika, 45, 357-372.

Schneider, B., \& Bissett, R. (1988). "Ratio" and "difference" judgments for length, area, and volume: Are there two classes of sensory continua? Journal of Experimental Psychology: Human Perception and Performance, 14, 503-512.

Schneider, B., Parker, S., Farrell, G., \& Kanow, G. (1976). The perceptual basis of loudness ratio judgments. Perception \& Psychophysics, 19, 309-320. https://doi.org/10.3758/ BF03204236

Shanteau, J. (1985, August). Application of information integration theory to methodology of theory development. Paper presented at the 
Ninety-Third Annual Convention of the American Psychological Association, Los Angeles, CA. (ERIC Document Reproduction Service No. ED 266-349)

Shih, R., Dubrowski, A., \& Carnahan, H. (2009). Evidence for haptic memory. In Third Joint Eurohaptics Conference and Symposium on Haptic Interfaces for Virtual Environment and Teleoperator Systems (pp. 145-149). Salt Lake City, UT: Institute of Electrical and Electronics Engineers.

Sprouse, J. (2011). A test of the cognitive assumptions of magnitude estimation: Commutativity does not hold for acceptability judgments. Language, 87, 274-288. https://doi.org/10.1353/lan.2011.0028

Stevens, J. C., \& Rubin, L. L. (1970). Psychophysical scales of apparent heaviness and the size-weight illusion. Perception \& Psychophysics, 8, 225-230.

Stevens, S. S. (1936). A scale for the measurement of a psychological magnitude: Loudness. Psychological Review, 43, 405-416.

Stevens, S. S. (1975). Psychophysics: Introduction to its perceptual, neu$\mathrm{ral}$, and social prospects. New York, NY: Wiley.

Stevens, S. S., \& Galanter, E. H. (1957). Ratio scales and category scales for a dozen perceptual continua. Journal of Experimental Psychology, 54, 577-411.

Stevens, S. S., \& Guirao, M. (1963). Subjective scaling of length and area and the matching of length to loudness and brightness. Journal of Experimental Psychology, 66, 177-186.

Svenson, O., \& Åkesson, C. Å. (1966). Fractional and multiple estimates in ratio scaling (Report No. 202). Stockholm, Sweden: University of Stockholm, Psychological Laboratories.

Teghtsoonian, R. (2012). The standard model for perceived magnitude: A framework for (almost) everything known about it. American Journal of Psychology, 125, 165-174.

Utamura, S., Murase, C., Hamatani, Y., \& Nagano, Y. (2009). User experience index scale - Quantifying usability by magnitude estimation. Fujitsu Scientific \& Technical Journal, 45, 219-225.

Wagner, M. (2006). The geometries of visual space. Mahwah, NJ: Erlbaum.

Weiss, D. J. (2006). Analysis of variance and functional measurement: A practical guide. New York, NY: Oxford University Press.
Weiss, D. J. (2007). Extracting individual contributions to a team's performance. Teorie e Modelli, 12, 227-236.

Weiss, D. J. (2014). Evaluating cognitive models at the group level. Psicológica, 35, 405-422.

Weiss, D. J., \& Anderson, N. H. (1969). Subjective averaging of length with serial presentation. Journal of Experimental Psychology, 82, 52-63.

Weiss, D. J., \& Gardner, G. S. (1979). Subjective hypotenuse estimation: A test of the Pythagorean theorem. Perceptual and Motor Skills, 48, 607-615. https://doi.org/10.2466/pms. 1979.48.2.607

Westermann, R. (1982). Empirical test of scale type resulting from the power law for heaviness. Perceptual and Motor Skills, $55,1167-1173$.

Wilkening, F. (1981). Integrating velocity, time, and distance information: A developmental study. Cognitive Psychology, 13, 231-247.

Wilkening, F. (1982). Children's knowledge about time, distance and velocity interrelations. In W. J. Friedman (Ed.), The developmental psychology of time (pp. 87-112). New York, NY: Academic Press.

Wundt, W. (1907). Lectures on human and animal psychology. New York, NY: Macmillan. (Translated from the second German edition by J. E. Creighton and E. B. Titchener)

Zimmer, K. (2005). Examining the validity of numerical ratios in loudness fractionation. Perception \& Psychophysics, 67, 569-579. https://doi.org/10.3758/BF03193515

Zinnes, J. L., \& MacKay, D. B. (1989). Probabilistic multidimensional analysis of preference ratio judgments. In G. DeSoete, H. Feger, \& K. H. Klauer (Eds.), New developments in psychological choice modeling (pp. 177-205). Amsterdam, The Netherlands: North Holland.

Zwislocki, J. J. (2009). Sensory neuroscience: Four laws of psychophysics. New York, NY: Springer.

Publisher's note Springer Nature remains neutral with regard to jurisdictional claims in published maps and institutional affiliations. 